\title{
Norma, Economía y Lenguaje en el derecho de la crisis económica. El control judicial de la actividad administrativa en la economía. Algunas reflexiones
}

\author{
Antonio Embid Irujo \\ Catedrático de Derecho Administrativo \\ Universidad de Zaragoza (España) \\ aembid@unizar.es
}

\begin{abstract}
Resumen
La crisis económica ha realzado el interés del estudio jurídico de la actividad económica frente al predominio tradicional del papel de los economistas. Las palabras utilizadas por el derecho de la crisis no siempre son neutras sino que aparecen, usualmente, con una connotación valorativa nada clara. Eso sucede singularmente con la "racionalización" o la "sostenibilidad", no susceptibles de valoración unívoca, como la misma evolución de este derecho prueba. Por otra parte y a partir del lenguaje usado, el control judicial de la actividad económica se hace especialmente difícil, como se muestra en alguna sentencia del Tribunal Constitucional.

Palabras Clave

Racionalización; sostenibilidad; uso racional de los recursos naturales; arbitrariedad del Legislador; discrecionalidad administrativa.
\end{abstract}

\section{Standard, Economy and Language in the law of the economic crisis. Judicial review of administrative activity in the economy. Some Reflections}

Abstract

The economic crisis has emphasized the interest of a juridical study of economic activity, opposed to the traditionally predominant role of the economists on the matter. Words used by the law of the crisis are not all ways neutral, implying usually unclear values. This happens with words as "rationalization" or "sustainability", which as their juridical evolution proofs, remain undeterminate concepts. Besides, as is shown on some decissions of the Constitutional Court, this unclear use of lenguage makes judicial control on economic activities quite difficult.

Keywords

Rationalization, sustainability, rational use of natural ressources, normative arbitrariness, amministrative discretionality.

SUMARIO: I. PROPÓSITOS.- II. SOBRE LA RELACIÓN QUE ACTUALMENTE PUEDE ESTABLECERSE ENTRE DERECHO Y ECONOMÍA. ALGUNAS CONSECUENCIAS. - III. EL LENGUAJE DEL DERECHO DE LA CRISIS ECONÓMICA. RACIONALIZACIÓN Y SOSTENIBILIDAD: 1. LA PRESENTACIÓN NORMATIVA DE LA RACIONALIZACIÓN Y DE LA SOSTENIBILIDAD: SU VINCULACIÓN REAL A LA REDUCCIÓN DEL DÉFICIT PÚBLICO. UN EJEMPLO A DESTACAR EN LA RECIENTE REFORMA NORMATIVA DE LA ADMINISTRACIÓN LOCAL; 2. LO PERMANENTE DE LA APELACIÓN A LA RACIONALIZACIÓN DENTRO Y FUERA DEL DERECHO DE LA ECONOMÍA. LO RACIONAL EN LA UTILIZACIÓN DE LOS RECURSOS NATURALES Y, SINGULARMENTE, DEL AGUA; 3. INDAGACIONES NADA FILOLÓGICAS-Y TAMBIÉN POCO JURÍDICAS- SOBRE LOS CONCEPTOS DE RACIONALIDAD Y DE RACIONALIZACIÓN EN EL DERECHO DE LA CRISIS ECONÓMICA A PARTIR DE LA INEXISTENCIA DE UNA DEFINICIÓN NORMATIVA; 4. LA DEFINICIÓN NORMATIVA DE LO QUE ES SOSTENIBILIDAD. UNA CONSTATACIÓN: LA VARIABILIDAD DE TAL CONCEPTO; 5. LAS LEYES Y SUS TÍTULOS: LO DESCRIPTIVO Y LO NEUTRO. LO VALORATIVO Y LO ORIENTADO; 6. DIVAGACIONES SOBRE LA TEORÍA DE LOS CONCEPTOS JURÍDICOS INDETERMINADOS. ALGUNAS PREGUNTAS SOBRE LO QUE PUEDA SER RACIONAL Y SOSTENIBLE EN EL ÁMBITO DE LA ORGANIZACIÓN TERRITORIAL DEL ESTADO Y DEL SISTEMA FINANCIERO.- IV. Y FINAL: EL CONTROL DE LA ARBITRARIEDAD DEL LEGISLADOR EN LA CRISIS ECONÓMICA: EL EJEMPLO DE LA SENTENCIA DEL TRIBUNAL CONSTITUCIONAL 206/2013, DE 5 DE DICIEMBRE.- BIBLIOGRAFÍA. 


\section{PROPÓSITOS}

Son muy diversos temas los que se anuncian en el título de este trabajo y cuyo contenido se corresponde en sus grandes líneas con mi intervención oral en el Seminario que el pasado 30 de enero de 2014 y bajo la dirección del profesor Santiago Muñoz Machado tuvo lugar en el Centro de Estudios Políticos y Constitucionales, en una sesión francamente interesante y de la que el autor de estas líneas es, ante todo, deudor por las múltiples informaciones y ocasión de variadas reflexiones que se expusieron en ella por los diversos ponentes y asistentes.

Mi intervención no tuvo un objeto concreto, como se podrá deducir muy bien por el título que he puesto a este pequeño trabajo, sino que aproveché la ocasión para sintetizar de una forma medianamente articulada, algunas de las reflexiones que la peculiar situación jurídica creada tras la oficialización en nuestro país de la crisis económica (verano de 2008) y anticipada por la crisis que, en realidad, se origina en Estados Unidos y en algunos países o, más bien, sectores económicos (financieros) de Europa un año antes, me ha venido suscitando, normalmente de la mano de la redacción de algunos trabajos en los que se estudian las novedades normativas de la crisis que alcanzan su cénit -en lo que a España se refiere- en la reforma constitucional de septiembre de 2011 y en los paralelos Tratados con los que Europa trata de adaptar su estructura jurídico-constitucional (utilicemos la palabra maldita a escala europea) a las urgencias y ansiedades de la crisis'.

La ocasión de dedicar un amplio período y tiempo de mi actividad investigadora a esta cuestión radicaba (y radica) en el pleno convencimiento de que esa crisis económica iniciada en los años 2007-2008 tenía rasgos comunes, sí, con otras sucedidas con anterioridad, pero presentaba unas características nuevas, distintas de todo lo que se había conocido hasta el momento, que justificaban una consideración especial², también desde el plano jurídico. Se trataba, efectivamente, de la primera crisis económica (inicialmente de extensión prácticamente mundial) desarrollada en tiempos de plena globalización ${ }^{3}$ y, particularmente y en el plano europeo, era también la primera crisis que tenía lugar tras la instauración de la moneda única y la cesión por parte de los países miembros de esa moneda (y también, aun en una medida inferior, de los otros) de importantes competencias en el campo de la actividad económica (no solo de la política monetaria) a órganos e instituciones europeas. El hecho de que pasado un tiempo y desde más o menos 2010-2011, la crisis se haya centrado casi con exclusividad en Europa, afianza las razones por las que desde Europa debe prestarse una especial atención a esta crisis y permite reflexionar sobre la adecuación de las actuales normas y estructuras para enfrentar situaciones de este cariz. Obviamente las reflexiones tienen que tener un asiento especial en los juristas que, sobre todo y tratándose de los especializados en derecho público, deben atender a las transformaciones que ello está ocasionando en las estructuras jurídicas tradicionales nacionales y europeas ${ }^{4}$, transformaciones que, obviamente, no están limitadas al derecho público ni al "constitucional" europeo5.

Ahora lo que pretendo es plasmar unas nuevas reflexiones sobre las relaciones que desde la perspectiva jurídica pueden establecerse con el lenguaje utilizado por las normas y con, en general, el desarrollo de la actividad económica o la Economía, sin más. Concluiré estas páginas con algunas ideas dedicadas al control judicial de las decisiones adoptadas en el tiempo de la crisis económica, un aspecto que siempre e inevitablemente tiene que estar presente en el trabajo de cualquier jurista plenamente convencido de las bondades del Estado de Derecho que anuncia nuestra Constitución ${ }^{6}$.

\section{SOBRE LA RELACIÓN QUE ACTUALMENTE PUEDE ESTABLECERSE ENTRE DERECHO Y ECONOMÍA. ALGUNAS CONSECUENCIAS.}

La relación entre Derecho y Economía ha sido objeto de continuas y variadas atenciones doctrinales. Éstas

1 La cita no tiene más objeto que enmarcar el ámbito y objeto personal de preocupaciones investigadoras. Vid., así, mis trabajos publicados en 2009, 2011 y 2012 cit. en la bibliografía final

2 Cfr. para una historia de las crisis financieras C. MARICHAL (2012): in totum. Sobre las características específicas de la crisis en su manifestación financiera vid. G. DE LA DEHESA (2009), especialmente pp. 55 y ss.

3 Para la descripción (jurídica) de lo que significa un sistema económico globalizado y con anterioridad a la crisis, vid. D’ALBERTI (2008). También CASSESE (2009). Ya plenamente en el marco de la crisis económica MALARET (2013).

4 Tempranamente CAZORLA PRIETO (2009) y posteriormente también en su discurso de ingreso en la Real Academia de Legislación y Jurisprudencia (2010). Igualmente vid. RODRIGUEZ DE SANTIAGO y VELASCO CABALLERO (2010), también y volcado sobre el derecho positivo en trance de transformación el trabajo de VILLAR ROJAS (2013). Desde la perspectiva europea vid. MIGUEL BÁRCENA (2011), SOSA WAGNER y FUERTES (2011), MENÉNDEZ (2012), CARRERA HERNÁNDEZ (2013) y BALAGUER CALLEJÓN (2013). En un plano menos jurídico pero con un pensamiento propio social, económico y con su transcendencia jurídica, OFFE (2013), trabajo altamente recomendable desde variados puntos de vista. Sobre la reforma de la Constitución específicamente y además de lo ya citado anteriormente vid. ALVAREZ CONDE y SOUTO GALVÁN (2012), BASSOLS COMA (2012) y GARCIA ROCA Y MARTINEZ LAGO (2013).

5 Cfr. J.M. EMBID IRUJO (2013) en lo relativo a los impactos de la crisis sobre el derecho de sociedades.

6 El método de trabajo utilizado creo que justifica las escasas citas doctrinales que se van a llevar a cabo en relación a lo mucho publicado sobre la cuestión y, desde luego, la práctica ausencia de las referencias básicas de la doctrina jurídica que podríamos denominar como "clásica" en torno a las grandes cuestiones que aquí se mencionan. 
han tenido lugar usualmente en el marco de los trabajos que se han desarrollado para estudiar y explicar lo que podría llamarse, genéricamente, como “intervención del Estado en la economía” (o intervención administrativa, de la Administración, de los poderes públicos etc... en la economía), sobre todo tras la segunda guerra mundial, que es el momento en el que con más intensidad, incomparable desde el punto de vista de la evolución histórica, comienza a tener lugar esa intervención administrativa "directa” en la economía”.

Los trabajos basilares en cada país se han solido estructurar bajo el principio de descripción de la llamada "Constitución económica", y han versado sobre la indagación en el contenido de aquellos preceptos que dentro de cada Constitución se referían a las cuestiones básicas sobre el sistema económico. Tomando como punto de partida la imitación de la doctrina alemana, precursora en estas cuestiones", los trabajos que se mueven en el ámbito del estudio de la "Constitución económica" se dedican a indagar, fundamentalmente, el grado de precisión con el que se dibuja por las Constituciones un sistema económico, la libertad con que el constituyente deja al legislador, el marco jurídico de la planificación económica y el tipo de planificación económica que se dibuja en los correspondientes preceptos etc ${ }^{10} . .$. El resultado global de estas indagaciones suele concluir en el amplio espacio dejado por las Constituciones al Legislador (y a la Administración) aun dentro de las premisas que genéricamente suelen (solían) denominarse como de "economía social de mercado"”1"

En todo caso y sin más precisiones podríamos destacar dos características básicas de ese análisis que he llamado tradicional. Es la primera la de la posición subordinada, instrumental o auxiliar, que en todo caso han tenido los análisis jurídicos en relación a los realizados desde el punto de vista de la ciencia económica (a) y la segunda que el discurrir del jurista versaba siempre sobre economías nacionales y marcos jurídicos nacionales también; la referencia a la clásica expresión "Constitución económica", entendida textualmente, muestra el limitado marco territorial de lo que se estaba tratando (b).

Profundizando un poco más en la primera idea, solía ser usual la presentación del trabajo del jurista como auxiliar del propio de la ciencia económica. Incluso y sin tal tipo de presentación, flotaba en el ambiente profesional tal consideración, y no digamos en el académico ${ }^{12}$. Y ello vinculado al hecho de la importancia suprema que en el plano de la práctica tenían las decisiones económicas -que, obviamente, también eran decisiones políticas, sea concretas o estructurales, permanentes o, al menos, con vocación de permanencia. Los estudios jurídicos venían, posteriormente, a explicar dichas decisiones económicas, a exponer el marco jurídico en el que debían entenderse, a insertarlas -si eran trascedentes- en la evolución histórica de las funciones del Estado.

A veces la explicación jurídica precedía a la decisión económica. Eso sucedía en los puros estudios sobre la "Constitución económica" que, como ya he indicado, querían fundamentalmente referir el tipo de decisiones que podían adoptar los poderes económicos dado el concreto sistema dibujado por las normas incluibles en tal Cons-

7 Pues indirecta, desde el punto de vista regulatorio (creación de normas, sin más) o del fomento, naturalmente que había tenido lugar ya con anterioridad. Desde el plano puramente académico, de la asignatura que se llama Derecho Administrativo en los distintos planes de estudio, basta con decir que es en este momento cuando se puede añadir una nueva función definitoria del papel cumplido por la Administración Pública. A las tradicionales funciones de policía, fomento y servicio público (aparecidas o, más bien, teorizadas también en un orden cronológico) ahora se suma como novedad todo el mundo de la norma (regulación en sentido estricto), organizativo, práctico, de la intervención directa en la economía marcada por la creación masiva de empresas públicas para construir barcos, producir acero, automóviles, energía etc.. en casi todos los países europeos.

8 Vid. para España BASSOLS COMA (1985) y la “nota preliminar”, más que sugerente, de S. MARTíN-RETORTILLO en su excelente Derecho Administrativo económico (1991, pp. 5 y ss.). Vid. la conexión que sienta STOBER entre Derecho constitucional económico y Derecho administrativo económico (1992, pp. 47 y ss.), que luego está presente en el resto de su obra. Ya plenamente en el marco europeo CASSESE (2012) y su significativa incidencia en la "nueva" Constitución económica. Sin adjetivos calificativos, pero plenamente imbuido de la necesidad de estudio de la normativa europea, vid. el libro editado por la Asociación de Letrados del Tribunal Constitucional (2012). 303 y ss.)

9 Una síntesis valorativa más que útil acerca de las concepciones doctrinales en Alemania en el trabajo de MONGOUACHON (2012, pp.

10 Mundo éste de la planificación económica de gran importancia en el pasado en los estudios sobre la intervención administrativa en la economía y hoy, aun presente en las Constituciones (vid. el art.131 CE) en la práctica completamente desgajado (sin raíces comunicadoras) del tronco normativo común. Lo que no quiere decir que algún día no pudiera revivir (cosas más raras se han visto en la evolución de las instituciones jurídicas) pero ello no parece en modo alguno previsible ni siquiera a medio plazo, al menos en países como el nuestro. En algunos latinoamericanos, sin embargo, la planificación de la economía goza de un saludable vigor, al menos teórico.

11 Precursor en el calificativo de economía social de mercado del sistema creado por la Ley Fundamental de Bonn, es NIPPERDEY en numerosos trabajos, aquí me refiero al publicado en (1950). En otras ocasiones se concluye en la neutralidad económica de la Constitución (en el sentido de tolerancia), o en la ausencia de prescripciones que conduzcan a un sistema concreto (vid otra vez MONGUACHON, 2012, pp 312 y ss.). Saltando de la referencia alemana, en algún trabajo de evidente mérito (y por eso procedo aquí a su cita) el dato constitucional aparece inicialmente camuflado por la referencia sociológica que se establece como prioritaria (el Estado censitario, el Estado burgués, el Estado interclasista... ) pero inmediatamente, y cuando tiene que estudiarse detenidamente el fondo del asunto, surge la Constitución como premisa indiscutible del análisis (que en la obra que menciono es, literalmente, extraordinario). Vid. así. GIANNINI (1977, 1993 en la edición por la que cito).

12 Es curioso constatar la desaparición casi generalizada de la asignatura llamada tradicionalmente "Derecho Administrativo Económico" en los planes de estudio de las titulaciones que se imparten en las Facultades usualmente denominadas como de Ciencias Económicas. Esta realidad ya es intuida por S. MARTIN-RETORTILLO (1991) en su nota preliminar. 
titución a cuyos efectos debía describirse con minuciosidad el "sistema” económico creado por la norma suprema del ordenamiento jurídico.

También el jurista, con su conocimiento histórico sobre la evolución de los marcos jurídicos de la economía, explicaba lo novedoso y lo tradicional, las rupturas (reformas más bien) y las continuidades. Normalmente eso servía para rebajar las expectativas y resultados de las ansias "rompedoras" de economistas excesivamente dogmáticos. En ese contexto es también posible que el discurrir jurídico pudiera ser crítico de algunas decisiones económicas extendiéndose a señalar cómo concretas decisiones económico-políticas podían ser incompatibles con ese marco constitucional. Por ejemplo y en épocas pasadas, algunos señalaron en España que la llamada "huida del derecho administrativo", acompañante parece que necesario de la creación de múltiples empresas públicas o entidades de derecho público, podría considerarse contraria a determinadas premisas constitucionales sobre el papel de los poderes públicos, su posición respecto a la actuación de los Tribunales contencioso-administrativos como preferentes en el control judicial de la Administración Pública respecto al papel que pudieran jugar los órganos de la jurisdicción ordinaria, que serían aquéllos en los que, dada esa "huida del derecho administrativo" debería recaer de forma predominante el control de la actuación de una Administración sin derecho (administrativo).

En todo caso y de una forma u otra, creo que es conveniente resaltar e insistir en el elemento auxiliar con el que se presentaba al discurso jurídico siempre bajo la égida del decisionismo económico. Incluso su carácter muchas veces voluntariamente sumiso, de subordinación, ante "la verdadera ciencia” que sería la económica (como así han pensado y piensan muchos economistas).

El derecho, en este ámbito que describo con trazos tan gruesos, sería cosa de los "leguleyos", es decir de aquéllos a los que solo parece preocupar la obstaculización de las decisiones que dentro de un saber propio e inequívocamente digno de respeto adoptan los economistas-políticos. Juristas que utilizan, además, un lenguaje incomprensible, enteramente artificial; así decían y dicen algunos.

Y además y en todo caso, nos encontraríamos ante tratamientos jurídicos de planteamientos económicos que se desarrollarían en un plano territorial exclusivamente nacional.

La presente crisis económica ha matizado enormemente las dos premisas de las que acabo de partir.

a) En primer lugar y como punto fundamental porque esta crisis nos ha convencido a todos, y los primeros a los juristas -al menos a los que necesitaran de tal convencimiento-, de que nuestro trabajo no estaba subordinado a la "verdadera ciencia", pues prácticamente ningún economista (salvo Roubini) había llamado la atención sobre la posible generación de una crisis de esta índole ${ }^{13}$. Ni los economistas apellidados (por ellos o por sus contrarios) como "neoliberales" ni los más partidarios de una significativa intervención del Estado en la vida económica14. Con ese convencimiento los juristas hemos perdido alguno de los complejos que antes nos atenazaban y entrado, sin miedo alguno, a analizar determinados elementos de la crisis, los que podíamos dominar con relativa seguridad dada nuestra formación previa.

Ello, como digo, en los múltiples aspectos en los que nuestro trabajo puede desarrollarse y, fundamentalmente, en el análisis de los condicionamientos jurídicos que lleva consigo la moneda única en Europa y la consiguiente centralización de la política monetaria; también en el plano de la ausencia -en las normas europeas- de otras políticas elementales (fiscal, presupuestaria) para conducir con relativa seguridad la vida económica, políticas que siguen estando entregadas a los ámbitos nacionales bien que con notables limitaciones en la tradicional discrecionalidad de que gozaban ${ }^{15}$. Con esto, y aunque parezca paradójico, se ha propiciado que los juristas hayamos podido estudiar y describir nuevamente políticas aparentemente basadas en las de los “viejos tiempos" en los que el objeto del trabajo era la "intervención estatal en la economía” (o de los poderes públicos, o de la Administración)”. No (2010).

13 Por eso se ha hecho habitual una cierta literatura ácidamente crítica con el papel jugado por los economistas. Cfr. por todos PETRINI

14 Lo que no quiere decir que muchos economistas pertenecientes a estas tendencias no se hayan lanzado en una carrera ciertamente desaforada, a publicar múltiples libros en los que se explican minuciosamente las causas de la crisis (en ese ámbito del estudio puramente histórico hay que reconocer que los economistas presentan productos de un gran atractivo y que se leen con mucho gusto, lástima que no hubieran sido escritos antes de la producción del fenómeno) y también a determinar las soluciones para el futuro.

15 Limitaciones consistentes en la aprobación previa de marcos presupuestarios, seguimiento de las políticas nacionales con atención especial a la evolución de deuda y déficit desde el parámetro de la permanencia en el euro, señalamiento de críticas e inadecuaciones a planteamientos europeos y todavía más notables limitaciones para los países que han precisado de ayuda económica europea. Sobre ello últimamente vid. CARRERA (2013).

16 Aun cuando la reacción de las instituciones europeas a la crisis económica se hizo esperar mucho tiempo, cuando por fin empezaron a adoptarse decisiones -sobre todo en esos primeros días, angustiosos, del mes de mayo de 2010- se inició un período de fuerte intervencionismo que recuerda a las tradicionales políticas que se creían abandonadas desde el punto de vista de lo que significa el protagonismo de los poderes públicos frente al papel preponderante que los "mercados" habían tenido en los años precedentes. Bien es verdad que se trata de un intervencionismo concebido de forma temporal, para superar (o soslayar) una situación de fuerte crisis y en el que, de cuando en cuando, 
obstante se pueden señalar matizaciones en los distintos países, matizaciones que son muestra de los problemas particulares que se presentan en cada uno de ellos pero, globalmente, la necesidad del análisis jurídico del marco regulatorio se ha afianzado grandemente y dado lugar, además, a productos de gran calidad"7.

b) Y en segundo lugar por el hecho de que esta crisis, como ya se ha indicado supra, salta los límites nacionales y es distinta a las anteriores conocidas aunque pueda tener elementos comunes como siempre suele ser la existencia de una "burbuja" en un sector de la economía (en nuestro caso lo fue primero la burbuja inmobiliaria seguida rápidamente, como casi en una relación causa-efecto de la financiera) que estalla y determina la crisis.

Pero los elementos de globalización claramente de un lado y, por otra parte y de forma territorialmente parcial, el encontrarnos por primera vez ante una manifestación de crisis que golpeaba específicamente a países que se habían unido en torno a una moneda común y cedido, por lo tanto, a instancias supranacionales la política monetaria, la convertía en automáticamente distinta: y ello tanto en relación a la determinación última de las causas de la crisis como sobre los medios (y sus titulares) a utilizar en la lucha o reacción contra ella. Eso nos situaba, por las diferentes razones expuestas, ante algo radicalmente diferente a lo ya conocido ${ }^{18}$.

Consiguientemente se ha creado una relación de muy profunda interdependencia entre los marcos jurídicos nacional y europeo ${ }^{19}$. Los dos se necesitan; se puede decir que ninguno es completo sin el otro o que, más bien, lo completo (si se puede hablar de esta característica de forma apropiada) resulta de su suma necesaria ${ }^{20}$.

Una muestra excelente de lo que indico -un testigo, pero más que singular- lo encontramos en el Tratado de Estabilidad, Coordinación y Gobernanza en la Unión Económica y Monetaria de 2 de marzo de 2012 que dice en el art. 3.2 (dentro del Título III dedicado al Pacto presupuestario) que:

"Las normas establecidas en el apartado 1 se incorporarán al Derecho nacional de las Partes contratantes a más tardar un año después de la fecha de entrada en vigor del presente Tratado mediante disposiciones que tengan fuerza vinculante y sean de carácter permanente, preferentemente de rango constitucional, o cuyo respeto y cumplimiento estén de otro modo plenamente garantizados a lo largo de los procedimientos presupuestarios nacionales".

Y lo que dice el art. 3.1 -entre otras cosas- es que la situación presupuestaria de las Administraciones Públicas será de equilibrio o superávit y que esa premisa se considera respetada si el saldo estructural anual de éstas alcanza el objetivo nacional específico a medio plazo, definido en el Pacto de Estabilidad y Crecimiento revisado, con un límite inferior de déficit estructural del o'5\% del producto interior bruto a efectos de mercado.

Obligación, por tanto, de reformar las Constituciones -o normas de valor semejante-, obligación que no es meramente moral sino que debe cumplirse obligatoriamente a no ser que se arriesgue la imposición de penalida-

afloran de nuevo las timideces y las dificultades en el proceso de adopción de decisiones que parecen consustanciales al modo comunitario (o europeo) de actuación.

17 En este marco y en España nunca se dejará de resaltar suficientemente el valor de la aparición de la obra dirigida por el profesor MUÑOZ MACHADO, Derecho de la regulación económica (2009-2013). En el primero de los volúmenes, incluso, se apuntan ya determinados rasgos de la crisis económica de "2008” (vid. p. 62). En general en España se ha atendido, sobremanera, a los aspectos de la crisis económica manifestados en la crisis financiera, fundamentalmente en la manifestación relativa a la desaparición, práctica, de las Cajas de Ahorro, que formaban parte sustancial del sistema financiero.

18 Es curioso resaltar que durante los dos o tres primeros años de la crisis, que se presentaba como global, el papel de la agrupación de Estados que informalmente se llamaban G-8 o G-20, fue bastante importante. Posteriormente esas reuniones, cuando suceden y ello acontece cada vez más espaciadamente- no aportan ninguna consideración de interés, y el papel global que inicialmente intentó jugar el Fondo Monetario Internacional, se ha limitado, finalmente, a ser elemento cofinanciador -lo que no es baladí- de determinadas decisiones europeas. Esa característica de elemento prescindible tiene manifestaciones más curiosas, si cabe, en la reciente (y presente) crisis ucraniana en la que se ha llegado a suspender (me remito a distintos medios de comunicación) la presencia de la Federación Rusa en el G-8 lo que es muestra, en mi opinión, de la escasa consideración que se tiene sobre dicho club y en el interior del mismo, lo que no viene sino a corroborar lo ajustado del juicio general que se sienta en esta nota.

19 Esto no es un fenómeno nuevo, obviamente, sino que está ínsito en la propia fundación de las entonces llamadas Comunidades Europeas, pero nunca ha tenido tal profundidad como desde la creación de la moneda única y, desde luego, cuando las dificultades de la crisis económica que todavía se vive han llevado, incluso, a la obligatoriedad de la reforma de los marcos constitucionales nacionales para adaptarlos a las directrices que puedan surgir en el marco del respeto a los parámetros de deuda pública y déficit estructural, de las instituciones europeas. A ello me refiero más adelante en el texto.

20 Vid. sobre el particular los expresivos títulos de las ponencias de CALLIESS y SCHORKOPF en la reunión de 2011 de la Asociación Alemana de profesores de Derecho Público: "La crisis financiera como desafío para la creación de derecho en los planos internacional, europeo y nacional" (2012, pp. 115 y 184 y ss. respectivamente). El contenido de las ponencias responde plenamente a la expectativa que crea la lectura de su título. 
des por un procedimiento algo complejo ${ }^{21}$ pero teóricamente posible ${ }^{22}$.

La interdependencia que notaba es evidente y se ha demostrado, en España, con la reforma del art. $135 \mathrm{CE}$ que se anticipa temporalmente de forma notable a la entrada en vigor de este Tratado, pues los primeros pasos en la tramitación se dan en agosto de 2011 y se cierra todo ello a finales de septiembre del mismo año (el BOE del día 27 publica la reforma constitucional), es decir casi seis meses antes que sea jurídicamente vinculante la reforma constitucional por la aprobación del Tratado mencionado y con el contenido que se está indicando. Puede especularse sobre las razones que en España, al contrario que lo que sucedió en otros países como Italia ${ }^{23}$, impusieron tal aceleración que hoy ya sabemos que no se encontraban en la famosa carta del Presidente del Banco Central Europeo al Presidente del Gobierno del verano de 2011 y en cuyo contenido no se habla para nada de ello ${ }^{24}$. Una razón jurídico-política que no he leído hasta el momento en ningún lugar, pero cuya probabilidad no creo que deba rechazarse, ni mucho menos, es la "facilidad" relativa (real) de que tal reforma constitucional gozaba en aquél momento y las mayores dificultades que podría tener tras el próximo proceso electoral general que el entonces presidente del Gobierno ya había anunciado (y que se celebró el 20 de noviembre de 2011, menos de dos meses después de la reforma constitucional). Es claro que en el momento en el que fue realizada la reforma constitucional la suma del número de miembros de los Grupos Parlamentarios proponentes de la misma alcanzaba un número tal que imposibilitaba que el 10\% de los miembros de cualquiera de las Cámaras propusieran el referéndum al que se refiere el artículo 167 de la Constitución. Tras las elecciones generales de noviembre de 2011, ya era posible alcanzar ese número de hipotéticos proponentes del referéndum en el Congreso ${ }^{25}$.

\section{EL LENGUAJE DEL DERECHO DE LA CRISIS ECONÓMICA. RACIONALIZACIÓN Y SOSTENIBILIDAD.}

Avanzo un punto disponiéndome a tratar la siguiente cuestión anunciada en los propósitos iniciales de este trabajo (I). Lo que ahora me va a preocupar es incidir en algunos aspectos más que llamativos, en mi opinión, del lenguaje utilizado por el derecho de la crisis económica, lo que puede tener -y es lo que, sobre todo, me interesa resaltar- una trascendencia jurídica cuando todo un aparataje normativo quiere sustentarse sobre un lenguaje que, en mi opinión, no tiene los suficientes elementos de claridad y en algunas ocasiones, además, parece utilizado desde un punto de vista más político que jurídico lo que solo puede llevar consigo confusión e incertidumbre, justo lo contrario de lo que hay que pedir a la norma, a cualquier norma. Ello puede tener trascendencia específica cuando deba operar algún tipo de control judicial sobre la actividad administrativa desarrollada y basada en el lenguaje específico a que me refiero.

No cabe duda de que si hubiera que realizar una ordenación numérica (cuantitativa) de los conceptos utiliza-

21 Así, el art. 8 del Tratado dispone que la Comisión Europea presentará un informe sobre el cumplimiento por las Partes contratantes de esta obligación de reforma constitucional con el contenido indicado y si concluye que se ha incumplido tal obligación, el asunto podrá ser sometido al Tribunal de Justicia por cualquiera de las Partes contratantes. Cualquiera de éstas, también, podrá someter el asunto al Tribunal aunque el informe de la Comisión no haya constatado el incumplimiento. En ambos casos, "la sentencia del Tribunal de Justicia será vinculante para las partes en el procedimiento, que adoptarán las medidas necesarias para dar cumplimiento a la sentencia en el plazo que decida dicho Tribunal”. Finalmente, también la parte contratante puede solicitar del Tribunal de Justicia la imposición de sanciones pecuniarias cundo considere que, tras la Sentencia, ésta no se ha cumplido pudiendo llegar esas sanciones al o'1\% del respectivo Producto Interior Bruto, y cantidades que serán pagaderas al Mecanismo Europeo de Estabilidad.

22 Posible jurídicamente, aunque lo veo más que complicado en el plano de la realidad. Que la "solución" para aquéllos que incumplen parámetros de deuda y déficit por sus dificultades económicas pueda residir en la imposición de una penalidad económica, que no haría sino agravar los problemas originarios, se me antoja algo hipotética y, desde luego, de más que dudoso efecto práctico.

23 La reforma constitucional italiana para introducir el principio de estabilidad presupuestaria se hace por la Ley constitucional de 20 de abril de 2012 n. 1. En Francia no ha tenido lugar tal reforma constitucional. La reforma alemana se anticipó a 2009. Ello por hablar solamente de los países relevantes del euro.

24 Lo sabemos con seguridad tras la publicación del libro del anterior presidente del Gobierno, RODRIGUEZ ZAPATERO (2013) que incluye tal carta en inglés y con su traducción en castellano (vid. pp. 405 y ss.). Sobre el problema que trato el autor simplemente indica que pactó tal reforma con el líder de la oposición, el sr. RAJOY, tras recibir la carta y como una forma de responder a las preocupaciones de las instituciones europeas (y las consiguientes de los mercados) que la misiva llevaba consigo, pero en modo alguno se insinuaba, siquiera, la reforma constitucional en ese texto. En uno de mis trabajos (2012, vid. p. 65 nota 82) indiqué que probablemente la reforma constitucional podría responder al contenido de esa carta que en aquél momento nadie conocía (casi nadie, claro), al contrario de lo que sucedía con carta de contenido semejante que había recibido el Gobierno italiano y que fue hecha pública prontamente.

25 En la IX Legislatura de las Cortes Generales (2008-2011) la suma de miembros del Grupo Parlamentario Popular y del Socialista en el Congreso alcanzaba los 323 escaños sobre un total de 350. No existían, por lo tanto, 35 posibles proponentes del referéndum, a no ser que hubiera una bastante masiva ruptura de la disciplina de voto, cosa que en nuestro país es más que improbable. En el Senado era más grande todavía la mayoría pro-reforma al sumarse a los miembros de esos grupos los de Entesa Catalana de Progrés, compuesto mayoritariamente por senadores socialistas, y varios del mixto. En la X Legislatura en el Congreso de los Diputados el número acumulado de miembros de los Grupos Parlamentario Popular y Socialista es de solo 295, luego ya es teóricamente posible alcanzar, y holgadamente, esa cifra de 35 solicitantes de referéndum. Por eso en el texto me refiero a las mayores dificultades (la celebración de un referéndum) que habría podido tener la reforma constitucional realizada con posterioridad a las elecciones generales de noviembre de 2011 y tras la publicación del Tratado de marzo de 2012, cuando la necesidad de la reforma constitucional hubiera sido impuesta con vinculatoriedad jurídica por dicho Tratado. No hubo ocasión de plantear la sucesión cronológica entre Tratado y reforma constitucional española y, por tanto, de comprobar en la práctica lo que aquí aventuro. 
dos por el derecho de la crisis económica, los de racionalización y sostenibilidad estarían a la cabeza de todos ellos. Pero aunque pueda parecer sorprendente, dichos conceptos, al menos en su recogida en las normas correspondientes, no son de significado unívoco sino, al contrario, susceptibles de variadas interpretaciones y aun de mezclas entre ellos expresadas con escaso rigor como, de hecho, ha sucedido ya. Y también en alguna ocasión, nos encontramos con conceptos (como sucede con el de sostenibilidad) que varían en su contenido esencial en el tiempo en función de decisiones del propio legislador. En el fondo se ha producido y se sigue produciendo una interesada utilización de estos conceptos más acentuada en los últimos tiempos aun cuando no achacable, en su totalidad, a una única ideología política. Es posible, además, rastrear la utilización del concepto de "racionalización" en lo que se refiere a las reformas administrativas basadas en premisas económicas y aun en variados sectores normativos, muy atrás en el tiempo, lo que también debe dar lugar a reflexiones concretas.

Procedamos con el correspondiente análisis a explicitar de forma suficiente lo que en las anteriores líneas solamente se ha anunciado.

\section{LA PRESENTACIÓN NORMATIVA DE LA RACIONALIZACIÓN Y DE LA SOSTENIBILIDAD: SU VINCULACIÓN REAL A LA REDUCCIÓN DEL DÉFICIT PÚBLICO. UN EJEMPLO A DESTACAR EN LA RECIENTE REFORMA NORMATIVA DE LA ADMINISTRACIÓN LOCAL.}

Son numerosas las normas aprobadas tanto por el Estado como por las CCAA durante la crisis económica y que se acogen en su título, en expresiones de sus exposiciones de motivos o preámbulos o en el contenido de sus preceptos, al paraguas de la racionalización (sobre todo) pero también de la sostenibilidad (económica, financiera, presupuestaria, aquí suelen variar los predicados), lo que no quiere decir que siempre se distinga claramente entre ambos conceptos y que no se lleven a cabo, en múltiples ocasiones, mezcla de contenidos como tendremos cumplida ocasión de comprobar.

Una relación de normas acompañada de una propia indagación sobre el concepto de racionalidad o racionalización ya fue llevada a cabo, y brillantemente, por MONTOYA (2012) ${ }^{26}$ y no pretendo, en lo más mínimo, repetirla y mucho menos sustituirla. Hagamos notar, en todo caso, que la autora que menciono presentó su trabajo a la reunión de la Asociación Española de Profesores de Derecho Administrativo realizada en los primeros días de febrero de 2012 en Tarragona y que, por tanto, los datos y múltiples referencias que aporta tienen un claro tope temporal, el de su obra.

Dejando de lado otras cosas debo indicar en relación a lo que me parece más importante en el trabajo de MONTOYA -al menos desde el punto de vista de los objetivos que persigo en este artículo- que para ella el concepto de "racionalización" está vinculado a la "mejora del marco normativo, de la calidad de las normas, más claridad, menos confusión, simplificar y reducir la dispersión” (p. 50) y constituye un prius en relación al ejercicio de medidas de "reorganización", que pueden insertarse legítimamente en el ejercicio de la potestad organizatoria (p. 51). Racionalización y reorganización administrativa serían, por tanto, términos claramente distinguibles y sus contenidos podrían ser referidos a distintas normas que también nítidamente se engarzarían con uno u otro concepto27.

Nada que decir sobre ese criterio de distinción que me parece interesante e, incluso, hasta tiene visos indiscutibles elementos de lógica jurídica. Aventuro, en todo caso, que el ejemplo de la Ley 2/2011, de 4 de marzo, de Economía Sostenible, puede estar influyendo sobremanera en la posición doctrinal que refiero ${ }^{28}$. Así, me parece que lo previsto en los arts. 4-7 de dicha Ley y relativos a la llamada "mejora de la calidad de la regulación", formaría el amparo intelectual básico de lo que sería la "racionalización” para MONTOYA, mientras que, consiguientemente y por descarte, cualquier medida de impacto sobre el sector público (para su reducción) se encuadraría en el ámbito de la reorganización administrativa.

Sin querer discutir la racionalidad o razonabilidad (que no es exactamente lo mismo que la racionalización) de la distinción de que parte la autora, me parece que no siempre el Legislador o el Gobierno se comportan conforme a esas claras -cartesianas casi- reglas de división sistemática. Más bien lo que sucede es que la palabra "racionalización" sirve para amparar cualquier tipo de normativa o decisión administrativa dedicada a disminuir el gasto público y, consiguientemente, el déficit público (otra cosa es que lo consiga en la realidad, pero eso no constituye problema directo a tratar aquí) encuadrándose dentro de ellas, clara y francamente, las decisiones que conlleven la reducción de entidades públicas, tanto de las puramente administrativas como de empresas o entidades empre-

26 Trabajo en el que tomaba partido decidido por el proceso de racionalización en el sentido en el que ella defiende y que luego refiero en el texto. Obsérvese que incorpora al título de su trabajo la mención a la "inaplazable" hora de la racionalización que refiere, objetivamente, al "sector público instrumental".

27 La autora lleva a cabo a continuación el estudio de normas incluibles en una u otra categoría y también de normas que atenderían a ambos conceptos.

28 Vid. como prueba el contenido de la nota 78 del trabajo de la autora que refiero, con menciones expresas a dicha Ley. 
sariales, lo que es la clave del asunto, el contenido último y real, en la práctica, del concepto de racionalización, lo que no quiere decir que no pueda, también, aplicarse a otro tipo de medidas normativas con el mismo resultado -teórico- de reducción del déficit público.

Orientación, por tanto, muy sesgada de la práctica específica del concepto de racionalización que va precedida, además, de un deficiente planteamiento teórico de lo que tal concepto sea, como se puede observar en el plano de las definiciones en el que tal concepto y el de sostenibilidad aparecen mezclados y en distintas posiciones de ordenación entre sí. De esa forma y dentro de la misma Ley 2/2011, cuando se establecen los principios de acción de los poderes públicos para "impulsar la sostenibilidad de la economía española" (que es la rúbrica del art. 3) se indica que uno de ellos es el de "racionalización de las Administraciones públicas", principio que consistiría en la adopción de "medidas de simplificación y sostenibilidad de la estructura administrativa y de acceso directo de los ciudadanos a los servicios y prestaciones públicas garantizando una actuación ética, eficaz, eficiente y transparente", con lo que, como es fácil observar, el concepto de sostenibilidad sirve tanto para la definición del objetivo perseguido por la Ley como del medio para conseguir el objetivo, lo que no es muy correcto desde el punto de vista de la lógica jurídica (o de la lógica, sin más) ${ }^{29}$. Cuando, además, aparece en el mismo artículo y como otro de los principios para conseguir la sostenibilidad de la economía española el de la "racionalización de la construcción residencial" 30 , se puede empezar a sospechar lo que ya se ha indicado en este trabajo: el carácter nada objetivo, en modo alguno delimitador, del concepto de racionalización y su capacidad de aplicación a múltiples sectores, medidas y situaciones (un concepto que juega a la carta -el as- que posee el que es capaz de utilizarlo en cada momento) lo que supone, obviamente, un previo punto de partida acerca de lo que constituya la razón, la racionalidad, el contenido de la acción de racionalizar (o sea, la racionalización, como luego advertiré), a lo que iremos atendiendo sucesivamente en estas páginas. En todo caso lo que sí es seguro es que sea cual sea la norma en donde se utilice el concepto de "racionalización" estará vinculada al objetivo de reducir el déficit público (normalmente acompañado por la supresión de entidades administrativas, empresas u órganos de distinta índole) lo que también se conectará con la idea de "sostenibilidad" de las finanzas, del presupuesto, del sector público.

Lo que estoy indicando es fácilmente advertible en muchas de las normas que cita MONTOYA pero también en las posteriores a su trabajo y que, lógicamente, no pudieron ser estudiadas por la autora. Puede comprobarse en estos nuevos textos normativos -como aserto de lo que digo- que el concepto de "racionalización" ha sido aplicado normalmente a la reducción del número de entidades públicas, y en ese sentido se orientan ( $y$ no tengo la más mínima voluntad de exhaustividad en las referencias que siguen) el Decreto-ley 5/2013, de 22 de octubre, de medidas de racionalización y simplificación de la estructura del sector público de la Generalidad de Cataluña ${ }^{31}$, la Ley gallega 14/2013, de 26 de diciembre, de racionalización del sector público autonómico32, así como el todavía

29 Y se podría seguir señalando dentro de esta Ley 2/2011 otras incongruencias lógicas o, simplemente, la utilización acumulada de conceptos que, se supone, gozan de credibilidad por sí mismos. Así, el art. 32.2 indica que "para garantizar la sostenibilidad presupuestaria, las Administraciones Públicas aplicarán una política de racionalización y contención del gasto y se adecuarán a los principios de estabilidad presupuestaria, transparencia, plurianualidad y eficacia, en los términos definidos en la normativa de estabilidad presupuestaria". Los resaltes tipográficos son míos, obviamente.

30 La referencia a la "construcción residencial” podría (y puede) sorprender dentro de la enumeración de principios que, parece, tienen un corte sustancialmente económico pero es compatible con la burbuja (y el desastre consiguiente) inmobiliario que ya había surgido. Obsérvese que para la Ley 2/2011 la racionalización de la construcción residencial consiste en la adopción de medidas por parte de las Administraciones Públicas "que favorezcan la racionalización de la construcción residencial para conciliar la atención a las necesidades de la población, la rehabilitación de las viviendas y de los núcleos urbanos, la protección al medio ambiente y el uso racional de los recursos económicos". Otra vez en esta definición aparece el objetivo a conseguir unificado con el medio para ser conseguido, y esta vez por dos veces como se puede observar con mis resaltes tipográficos. La gran cuestión es, obviamente, la determinación de qué sea la racionalización, tanto de forma general como en sus aplicaciones concretas, ahora en relación a la construcción residencial. Porque lo que el precepto dice, sin más, es que el objetivo de la racionalización de la construcción residencial hay que conseguirlo... mediante la racionalización de la construcción residencial y el uso racional de los recursos económicos". Expresión absolutamente inane, por tanto, en relación a cualquier esfuerzo intelectual sobre el significado de los conceptos y de los mandatos jurídicos pero, creo, altamente representativa de la vaciedad con la que, en la mayor parte de las ocasiones, se manejan estos conceptos (y sus consecuencias, lo que es mucho más importante).

31 Texto exclusivamente dedicado a la reducción de entidades del sector público (vid. su Título I) o a algo que puede jugar de forma relativamente parecida, como la "extinción de la personalidad jurídica de entidades" (Título II), o la modificación de adscripción, de funciones y de composición de entidades (Título III) así como de "medidas sobre el endeudamiento de las entidades del sector público en proceso de racionalización, reducción y simplificación" (art. 9 que es el único del Título IV). Todo ello y como dice el preámbulo del Decreto-Ley respondiendo a su mismo título sirve a la "simplificación" del sector público de la Generalidad, siendo el de simplificación un nuevo concepto a tener en cuenta y que también vamos a observar en otros textos normativos y que pareciera, por usarse de forma acumulativa con el de "racionalización", tener un contenido distinto. No es así.

32 La Exposición de Motivos de este texto es clarividente acerca de lo que significa racionalización para el Parlamento origen de la Ley: “La optimización de los recursos públicos, la eficacia en la gestión y el logro de la máxima coordinación de las distintas unidades administrativas son principios básicos que guían la actuación de la Xunta de Galicia. En aplicación de estos principios, en el año 2009 se inició un proceso gradual de racionalización, simplificación y reducción de las estructuras administrativas, tanto en lo que atañe a la Administración general como al conjunto de entidades públicas instrumentales del sector público autonómico. Así, se abordó una reducción del $40 \%$ en el número de consejerías, se impulsó un nuevo diseño de la Administración periférica con cinco únicas delegaciones territoriales, se redujo a la mitad el número de altos cargos y se ejecutó un completo plan para adelgazar la dimensión de la Administración instrumental”. Una pregunta inocente: 
(cuando se escriben estas líneas) Proyecto de Ley (estatal) de racionalización del sector público y otras medidas de reforma administrativa (BOCG-CD de 7 de febrero de 2014, núm. 79-1) en el que la equiparación de racionalización con supresión de entidades públicas es expresa ${ }^{33}$. Este último texto se debe entender vinculado a las medidas ya acordadas por la Comisión para la Reforma de las Administraciones Públicas (CORA) creada a finales de octubre de 2012 por el Consejo de Ministros, como así indica su preámbulo o exposición de motivos ${ }^{34}$.

Pero de la misma forma se ha utilizado el concepto de racionalización para llevar a cabo otros objetivos, como en lo relativo a poder decidir sobre las solicitudes de prolongación de los funcionarios en el servicio activo más allá de la edad de jubilación ( 65 años) $)^{35}$ o también importantes innovaciones en el régimen jurídico de la enseñanza y ello igualmente con el objetivo de disminuir el gasto público. Ese es, precisamente, el objeto del Real Decreto-ley 14/2012, de 20 de abril, de medidas urgentes de racionalización del gasto público en el ámbito educativo, con contenido variopinto ${ }^{36}$.

Y por concluir en la narración de significativos textos en la línea que se indica lo debo hacer mencionando la Ley 27/2013, de 27 de diciembre, de racionalización y sostenibilidad de la Administración Local, donde los dos conceptos sobre los que se especula en esta parte del trabajo (racionalización y sostenibilidad) se incorporan al mismo título de la Ley siendo sus elementos definitorios. Ley que está concebida claramente bajo los parámetros de reducción del déficit público bien que en este supuesto, y al contrario de lo que sucede con otras Administraciones Públicas, el déficit de las Corporaciones locales estaba ya más que contenido como se puede observar con el siguiente cuadro y con independencia de las cifras espectaculares de deuda (y déficit) que concretas Corporaciones Locales (el Ayuntamiento de Madrid, por ejemplo) puedan tener. A 31 de diciembre de 2012 (que es el parámetro temporal que se debería tener en cuenta dada la fecha de formulación del proyecto de Ley en septiembre de 2013) las Corporaciones Locales presentaban un déficit del o'22\% sobre el PIB y, además, en línea decreciente en relación al 31 de diciembre de 2011 en el que el déficit era casi el doble, el o'39\% del PIB. El avance que se ha presentado al Consejo de Ministros del 28 de marzo de 2014 sobre las cifras a 31 de diciembre de 2013 ya refleja lo que era previsible con la anterior evolución: que en las entidades locales lo que existe en este momento es superávit37. No cabe duda de que en estas circunstancias, acudir al parámetro de la "racionalización" para justificar una intervención normativa es perfectamente posible, por supuesto, pero debe tratarse de una racionalización (y sostenibilidad) de distinto signo finalista de la contemplada en el resto de las normas citadas en este punto y, en todo caso, de la aplicable a otras Administraciones Públicas.

¿la racionalización consistía en reducir un 40\% el número de consejerías? ¿No sería, mejor, un 35\% o, quizás, un 45\%?

33 Vid. el punto I del preámbulo o exposición de motivos (no hay denominación en el proyecto de Ley) en donde se habla de la insostenibilidad del sector público como consecuencia de la reducción de ingresos y, por tanto, de "la racionalización de la estructura de la Administración Pública, como parte del programa de reformas del Gobierno”. Los ejemplos de entidades a suprimir en este Proyecto de Ley estatal no son, precisamente, de los de más abundante vía administrativa (se trata de la Obra Pía de los Santos Lugares y de otros ejemplos similares) no existiendo en el preámbulo o exposición de motivos presencia del ahorro que se va a conseguir, presumiblemente, con tales actuaciones; probablemente esas cifras estarán en la memoria con la que el Gobierno habrá acompañado el envío del Proyecto de Ley al Congreso de los Diputados.

34 El tema de la actuación de esta Comisión es asaz interesante, pero no puede ser enfrentado aquí. Baste con referirse al Informe de la subcomisión de duplicidades administrativas (borrador de 18 de noviembre de 2013) y, sobre todo, al Informe anual de seguimiento de las medidas de la Comisión para la reforma de las Administraciones Públicas, de 17 de enero de 2014. Ambos accesibles en la página web del Ministerio.

35 En este caso el ejemplo es referido a la Comunidad Autónoma de Aragón. La Ley 7/2012, de 4 de octubre, en su disposición final primera, añade una disposición adicional $19^{\mathrm{a}}$ al Texto Refundido de la Ley de la Función Pública de la Comunidad Autónoma de Aragón (aprobado por el Decreto Legislativo 1/1991, de 4 de febrero), indicando que las solicitudes de prolongación de la permanencia en el servicio público hasta los 70 años de edad se resolverán motivadamente por la Administración Pública con arreglo a determinados criterios y, entre ellos, las "causas organizativas, funcionales o presupuestarias, derivadas de la necesidad de racionalización de la estructura de puestos de trabajo y de estabilidad en la ordenación del personal de las Administraciones Públicas". El resalte tipográfico es mío y en unión con lo que luego se irá diciendo sobre este multifuncional concepto de "racionalización", podrá observarse que de ninguna forma es dable entender en qué pueda consistir el mismo aplicable a la estructura de puestos de trabajo y a las solicitudes de prolongación en el servicio activo hasta los setenta años de edad. Bajo ese paraguas cabe, es obvio, cualquier decisión.

36 En el texto preambular del Real Decreto-ley mencionado supra y tras el resumen de la exposición de las medidas se concluye en que "se trata, en definitiva, de introducir importantes elementos de racionalidad y eficiencia en el sistema educativo, que redundarán en una mejor prestación de este servicio público indispensable. Y se hace a través de medidas encaminadas a la consecución del equilibrio presupuestario...". En el ámbito universitario se incluyen dentro de estas medidas hasta las relativas a la dedicación horaria de los profesores en función de su éxito formal en la dedicación a la investigación.

37 Sobre el significado de todo ello en el contexto de un comentario general a la LRSAL vid. EMBID IRUJO (2014) donde se contienen diversos cuadros sobre la evolución de las cifras macroeconómicas de las Administraciones Públicas, pero también de los empleados públicos y otros datos necesarios para entender la aparición de la LRSAL. E insistiendo en los aspectos de sostenibilidad financiera en la Ley el excelente trabajo de JIMÉNEZ ASENSIO (2014). La LRSAL por su importancia ha sido objeto de múltiples estudios desde que solo era un borrador (el primero) y citar la bibliografía sobre ese proceso de elaboración sería inacabable. Por todos vid. los de FONT LLOVET y GALÁN GALÁN (2012) y DÍEZ DÍEZ (2013) trabajo este último con las ponencias de E. CARBONELL “La planta local: análisis general y perspectivas de reforma” y de M. ALMEIDA “La reforma de la planta, estructura competencial, organización y articulación de la Administración Local”. 


\begin{tabular}{|c|c|c|c|}
\hline Déficit \% PIB: & 2011 & 2012 & 2013 (avance) \\
\hline AGE & $-5 ’ 13 \%$ & $-3{ }^{\prime} 83 \%$ & $-5^{\prime} 49 \%($ con SS) \\
\hline CCAA & $-3 \cdot 41 \%$ & $-1,86 \%$ & $-1 ' 54 \%$ \\
\hline Entidades Locales & $-0,39 \%$ & $-0 \prime 22 \%$ & $+0{ }^{\prime} 41 \%$ \\
\hline Seguridad Social & $-0,07 \%$ & $-0 \prime 96 \%$ & (se incluye en AGE) \\
\hline Total AAPP & $-9,07 \%$ & $-6{ }^{\prime} 84 \%$ & $-6^{\prime} 62 \%$ (objetivo 6'5) \\
\hline Ayudas a Entidades de crédito & $-0,49 \%$ & $-3,80 \%$ & $+0{ }^{\prime} 46 \%$ \\
\hline TOTAL & $-9,56 \%$ & $-10 ' 63 \%$ & $-7 ’ 08 \%$ \\
\hline
\end{tabular}

FUENTE: Documentación presentada al Consejo de Ministros de 28 de marzo de 2014 e informaciones de años anteriores del Ministerio de Hacienda y Administraciones Públicas todo ello con elaboración propia ${ }^{38}$.

\title{
2. LO PERMANENTE DE LA APELACIÓN A LA RACIONALIZACIÓN DENTRO Y FUERA DEL DERECHO DE LA ECONO- MÍA. LO RACIONAL EN LA UTILIZACIÓN DE LOS RECURSOS NATURALES Y, SINGULARMENTE, DEL AGUA.
}

Pero como ya he advertido antes, el principio de la racionalización no es exclusivo en su utilización por el derecho de la presente crisis económica sino que la llamada justificadora a lo que "racionalmente" se decide se encuentra en otras normas aparecidas en muy distintos momentos. Así, y por seguir moviéndome dentro de los parámetros de la economía, puede recordarse la Ley 5/1996, de 10 de enero, de creación de determinadas entidades de derecho público. Ley muy importante e inserta, entre otras cosas, en la necesaria reacomodación de nuestro sector público como consecuencia de la presencia española en la Comunidad Europea y en los impulsos que en ese momento venían de Bruselas y que alentaban a recorrer, sin género de dudas, el camino de la privatización de las múltiples empresas públicas que todavía en aquélla época se dedicaban a la producción de bienes y servicios. El objetivo de estas páginas no es llevar a cabo la exégesis de una importante Ley cuyos efectos se desarrollarán durante muchos años ${ }^{39}$ sino notar, sin más, la apelación que a la racionalización se hace como amparo de sus medidas. Obsérvense los dos siguientes párrafos de su exposición de motivos en los que he llevado a cabo los convenientes resaltes tipográficos:

\begin{abstract}
"Sin embargo, la diversidad de situaciones en que se encontraban las empresas públicas del INI y, por consiguiente, las diferentes estrategias que exigía su actuación, unido a la necesidad de mejorar la gestión, determinó la conveniencia de proceder a una racionalización de las participaciones accionarias de que el Instituto era titular, diferenciando aquellas sociedades que eran susceptibles de ser gestionadas con criterios empresariales de aquellas otra sujetas en su actuación a regímenes especiales, derivados de su particular situación".
\end{abstract}

"Se trata, por consiguiente, de establecer una nueva ordenación institucional que permitirá racionalizar, globalmente, la gestión de las participaciones industriales de titularidad pública, coherente con las modificaciones que han conducido a la configuración del grupo INI/TENEO. A este fin se crean dos entidades de derecho público: la Agencia Industrial del Estado y la Sociedad Estatal de Participaciones Industriales"40.

Ahora bien, la conexión de estas previsiones con lo que vengo notando que siempre subyace a cualquier medida racionalizadora, la reducción del déficit público, es expresa:

"La urgencia de la medida viene dada por la creación de este nuevo marco institucional, que tendrá un efecto positivo en la reducción del déficit público...".

Y hay, finalmente, que convenir en que el redactor de la Ley 5/1996 confiesa con entera sinceridad en su exposición de motivos algo que ya podemos empezar a intuir sin ningún miedo a equivocarnos a estas alturas del trabajo: que la historia de la Administración (o sea, del derecho administrativo) es la historia de la racionalización (o, por lo menos, así suele presentarse en normas del tipo de las que comento). Lo que quiere decir que estamos

38 Hago notar mis dudas sobre la cifra total de déficit a fecha 31 de diciembre de 2013 (7’08\%) porque no advierto en esa cifra agregada coherencia con las cifras desagregadas. Si el déficit correspondiente a las ayudas a las entidades de crédito fuera negativo, entonces sí, pero la información está proporcionada de esa forma.

39 Vid. la inserción de la misma dentro de la narración de las transformaciones que experimenta la relación Estado-Sociedad en MUÑOZ MACHADO (2011, pp. 420 y ss).

40 Indica MUÑOZ MACHADO (2011, p. 420) que el propósito de esta Ley 5/1996 fue "la racionalización del sector público, distinguiendo, a tal efecto, las actividades sometidas a una regulación comunitaria específica de aquellas otras que actúan en mercados de libre competencia”. El resalte tipográfico es mío. 
ante una historia llena de fracasos parciales, al menos temporalmente hablando ${ }^{41}$. Veamos cómo se expresa ésta más que sugestiva idea en la exposición de motivos de esta Ley 5/1996:

"La racionalización del sector público es, pues, un proceso continuo cuyo fin último no es otro que la obtención de mayor eficiencia..."

Pero las menciones a la racionalidad no son exclusivas del derecho de la economía sino que pueden ser encontradas en sectores distintos del ordenamiento jurídico y en normas más que relevantes también. Obsérvese, así, el Tratado de Funcionamiento de la Unión Europea, que en su art. 191.1 recuerda (reproduce) un principio presente desde hace muchos años en el derecho originario al indicar que "La política de la Unión en el ámbito del medio ambiente contribuirá a alcanzar los siguientes objetivos:... la utilización prudente y racional de los recursos naturales"43.

Utilización racional de los recursos naturales que por influjo de las normas europeas (antes comunitarias) puede encontrarse también en el art. 45. 2 de la CE ("Los poderes públicos velarán por la utilización racional de todos los recursos naturales...") y a través de ella se desparrama en normas sectoriales distintas, como la legislación de aguas (ahora TRLA) donde la apelación al "uso racional" de las aguas es constante ${ }^{44}$. Ahora bien, en el TFUE, CE y TRLA, el uso racional es más que otra cosa una directriz que se establece por legislador tan relevante como el de estas normas para guiar la posterior labor de Legislativo y de Administración. Al contrario que la "racionalización" que en el derecho de la crisis económica (y en normas anteriores) hemos visto como justificador de las propias decisiones normativas adoptadas, en este caso lo que se está haciendo es marcar caminos que deben ser seguidos posteriormente por los poderes públicos en cada caso competentes. Ello determina, necesariamente, la realización de estudios jurídicos específicos para indagar qué es lo que se quiere decir por normas tan relevantes cuando se establece como objetivo a conseguir el del "uso racional" de los recursos naturales o de las aguas ${ }^{45}$. En este caso las decisiones adoptadas por el Legislador o la Administración deberán seguir a las normas que cito y estar plenamente justificadas, orientadas en el sentido del "uso racional", que marcan las normas directrices para lo que esos estudios indagativos (interpretativos) previos, son esenciales. En el derecho de la crisis económica, sin embargo, las decisiones que se enmarcan en normas de "racionalización" deben ser ejecutadas a la voz de ya, inexorablemente, porque son racionales, porque son el resultado del proceso previo seguido por el Legislador racionalizar, perseguir la racionalidad- para concluir en la adopción de tales medidas -racionalización-

Concluyo este punto resaltando esa identificación entre racionalización y justificación de las decisiones ya adoptadas por la norma que se reclama racionalizadora. En todo caso me parece que la importancia de lo que se va apuntando exige un pequeño punto en el que se sintetice la diferencia entre los conceptos de racionalidad y racionalización, al menos según mi modo de ver las cosas.

\section{INDAGACIONES NADA FILOLÓGICAS -Y TAMBIÉN POCO JURÍDICAS- SOBRE LOS CONCEPTOS DE RACIONALI- DAD Y DE RACIONALIZACIÓN EN EL DERECHO DE LA CRISIS ECONÓMICA A PARTIR DE LA INEXISTENCIA DE UNA DEFINICIÓN NORMATIVA.}

Lo interesante de la cuestión conceptual que estoy refiriendo llevó a MONTOYA en el trabajo que varias veces estoy refiriendo en este lugar al examen de la palabra "racionalizar" según el Diccionario de la Real Academia Española y a observar en él dos acepciones del vocablo. La primera sería la acción de reducir a normas o conceptos

41 Lo que no queda nunca claro en este texto (ni en otros), al menos expresamente, es quien adopta las medidas "irracionales" frente a las que hay que estar continuamente adoptando medidas de racionalización.

42 Casi podría encontrarse en esta frase un presupuesto metodológico para el estudio de la historia de la Administración pública. En términos de una cierta orientación para el investigador que aceptara este reto y método de trabajo (que yo rechazaría cortésmente si alguien me lo propusiera) sería conveniente recordar aquí el mito de Sísifo.

43 Por cierto que en la referencia del Tratado a la utilización "prudente" de los recursos naturales hay una invitación -algo larvada, bien es verdad- a la indagación comparativa con el principio prudencial en la gestión de las entidades financieras que tiene manifestaciones variadas como la "información de relevancia prudencial" que las entidades deben hacer pública como una de las consecuencias de los acuerdos de Basilea. En todo caso es claro que lo "prudente" en relación a la gestión de los recursos naturales conecta de forma natural con el significado del "principio de precaución” y en la línea de todo lo que estoy diciendo me ha llamado mucho la atención el estudio específico que hace CALLIES (2012, pp. 141 y ss.) del principio de precaución en relación con los riesgos del mercado financiero. ("Das Vorsorgeprinzip als Regulativ von Finanzmarktrisiken", como reza una de las divisiones sistemáticas de su trabajo).

44 Cfr. EMBID IRUJO (1997). En el trabajo afirmaba que la utilización racional de las aguas era la "cabecera espiritual del actual ordenamiento" (p. 209). Y de paso señalaba cómo dentro de la legislación histórica de aguas, podían encontrarse apelaciones a la racionalidad dentro del art. 167 la Ley de Aguas de 1879, con el siguiente contenido: “No se decretará la enajenación forzosa de aguas de propiedad particular para el abastecimiento de una población, sino cuando por el Ministerio de Fomento se haya declarado, en vista de los estudios practicados al efecto, que no hay aguas públicas que puedan ser racionalmente aplicadas al mismo objeto".

45 Eso es lo que hice en mi estudio de 1997 y en el que llegaba a la conclusión de que uso racional de las aguas era “.... expresión equivalente a la de menor consumo de agua, a política de calidad, a prohibición del abuso de derecho y desperdicio, a sustitución de unos caudales por otros etc... todo ello con la base común, insisto en la idea, de austeridad, ahorro, en el gasto de agua” (p. 210). 
racionales, y de ahí su conclusión de aspecto puramente normativo que tendría el concepto de "racionalización" para lo que le ayudaban determinados preceptos de la Ley 2/2011 de Economía Sostenible. La segunda acepción, más restringida, sería la acción de organizar la producción o el trabajo de manera que aumente los rendimientos o reduzca los costos con el mínimo esfuerzo, acepción que para la autora que sigo formaría el sustento del concepto de reordenación o de ejercicio de la potestad organizatoria ${ }^{46}$.

Naturalmente que este tipo de indagación debía realizarse a partir de una simple constatación: lo profuso de la utilización de los conceptos de racionalidad o de racionalización acompañada de la falta, absoluta, de definición normativa de lo que por tales pudiera entenderse, pues ya hemos visto, además, los groseros defectos lógicos del intento que a tales efectos realizó la Ley 2/2011 de Economía Sostenible (único intento, por cierto, hasta ahora de proceder a tal definición), incapaz de mantener, con un mínimo rigor, cualquier definición con visos de normatividad.

En todo caso ya he indicado con anterioridad que la estimable distinción conceptual de MONTOYA no se corresponde con la práctica que refleja el derecho de la crisis económica (incluso, como se habrá visto en el punto 2, también con normas anteriores). Más bien lo que creo se deduce de dichas normas es una distinción entre dos planos, igualmente temporales, correspondientes a las palabras "racionalidad" y "racionalización" referidas ambas a las medidas que se imaginan y pretenden adoptar.

En mi opinión la "racionalidad" de una medida, como característica ínsita a la misma, es una suerte de antecedente temporal de la norma de racionalización. Una medida es racional en tanto en cuanto se puede concluir o alcanzar en un puro proceso discursivo. Nosotros (lo digo en genérico, más bien los poderes públicos competentes para ello) apoyados en distintas artes y métodos de la lógica y presuponiendo el conocimiento del estado de la economía y de las técnicas propias de la ciencia económica, podemos llegar a la conclusión de que una determinada medida sería "racional" o no.

La "racionalización" sería el paso siguiente: el contenido normativo que conduce a hacer realidad lo que previamente se ha calificado como racional en el proceso deductivo previo. La racionalización sería la racionalidad en marcha, en pie de guerra, podría concluirse. Así, la Ley 27/2013, es plenamente una Ley de “racionalización” (así dice su título, al que añade el concepto de sostenibilidad) porque adopta decisiones explicitadas en forma de mandatos jurídicos para llevar a la realidad las medidas que, necesariamente, habrán sido imaginadas anteriormente en un proceso de deducción lógica, racional que, se supone, ya ha tenido lugar. En la misma Ley que se llama o que apela a la racionalización, está explícito lo que es racional, porque se trata de una Ley de racionalización y que, se supone, habrá elegido la mejor o mejores de las soluciones racionales previamente alcanzadas ${ }^{47}$.

En todo caso reitero el quicio que ha servido de partida de este punto: en ninguna norma está explicitado un concepto de racionalidad o de racionalización. Justo lo contrario de lo que sucede con el concepto de sostenibilidad.

\section{LA DEFINICIÓN NORMATIVA DE LO QUE ES SOSTENIBILIDAD. UNA CONSTATACIÓN: LA VARIABILIDAD DE TAL CONCEPTO.}

Como acabo de indicar y al contrario de lo que sucede con la racionalización, sí que hay una definición legal de lo que es la sostenibilidad (financiera). A ello procedió -en el derecho de la crisis económica- el art. 4 de la Ley Orgánica 2/2012, de 27 de abril, de Estabilidad Presupuestaria y Sostenibilidad Financiera que después de establecer en su apartado primero la sujeción de las Administraciones Públicas y de los demás sujetos comprendidos en dicha Ley al principio de sostenibilidad financiera, indicó en su apartado segundo que:

"Se entenderá por sostenibilidad financiera la capacidad para financiar compromisos de gasto presentes y futuros dentro de los límites de déficit y deuda pública, conforme a lo establecido en esta Ley y en la normativa europea" 48 .

Pero esta definición no ha estado vigente ni siquiera dos años, porque por medio de la Ley Orgánica 9/2013,

46 Las menciones de MONTOYA en las pp. 50 y 51. He confrontado las definiciones que usa en la vigésimo primera edición del DRAE de 1992 publicada en 1994.

47 Eso es un prius de cualquier legislador que se crea racional y que apele a la racionalización. Pero viene bien recordar aquí, otra vez, lo que con clarividencia expresó la Ley 5/1996 y que antes recordé acerca del proceso continuo que representa la racionalización del sector público.

48 Eso querría decir que el necesario proceso lógico-deductivo que indiqué que necesariamente debía aplicarse al concepto de racionalización, no tiene que ser realizado para el otro concepto clave del derecho de la crisis económica, la sostenibilidad financiera, sino que éste solo precisa del conocimiento de los datos de deuda y déficit de una Administración Pública y de la realización, posterior, del correspondiente proceso de subsunción. No saquemos conclusiones definitivas, sin embargo, y esperemos a ver cómo se desarrolla el proceso discursivo en el texto. 
de 20 de diciembre, de control de la deuda comercial en el sector público (art. 1.1), el apartado que acabo de transcribir sufrió una significativa modificación quedando redactado de la siguiente forma:

"Se entenderá por sostenibilidad financiera la capacidad para financiar compromisos de gasto presentes y futuros dentro de los límites de déficit, deuda pública y morosidad de deuda comercial, conforme a lo establecido en esta Ley, la normativa sobre morosidad y en la normativa europea". (Los resaltes tipográficos corresponden a la modificación operada por la LO 9/2013).

Las conclusiones que se pueden extraer a partir de esta modificación son bastante evidentes. Tenemos una definición legal de un concepto clave en el derecho de la crisis económica -sostenibilidad- pero mutable en el tiempo. Lo que sea sostenible hoy (escribo finalmente esta parte el 31 de marzo de 2014) no es lo mismo que lo que era sostenible ayer (antes del 20 de diciembre de 2013). O sea que una Administración Pública para la que podía aplicarse el concepto de sostenibilidad (y sus consecuencias, obviamente), el 19 de diciembre de 2013, puede ya no serlo el día 21 del mismo mes y año (y probablemente tampoco hoy, 31 de marzo de 2014) porque en ella se cumplirían, sí, los parámetros de déficit y deuda pública pero no las exigencias del nuevo concepto de morosidad comercial tal y como resulta de la Ley citada.

La pregunta es, entonces, obligada: ¿y mañana? ¿Qué nuevos elementos que hoy no conocemos podrán formar parte del concepto de sostenibilidad financiera dentro de un tiempo? ¿O se suprimirá alguno de los que hoy están incorporados? Obviamente esta interrogación nos lleva a poder plantear otra pregunta fundamental: ¿lo que sea sostenible financieramente puede, a su vez, ser conceptualmente cambiante? ¿Ser sostenible hoy pero no mañana y todo ello en función, solamente, de la imaginación del legislador en torno a la adición de condiciones específicas del concepto de sostenibilidad 49 ? ¿Tan maleable puede ser algo que parecía sustancialmente sólido, acompañado, obviamente, de las afirmaciones de economistas, evidentemente serios y algunos hasta con hablar engolado, en torno al juicio de sostenibilidad de una Administración? Porque, no se olvide, las consecuencias de que se afirme que una Administración es no sostenible financieramente, son tremendas y aparecen en la misma Ley Orgánica 8/2013 que estoy siguiendo.

La pregunta también nos podría llevar, en lógica congruencia con todo lo dicho hasta ahora, a formular una mucho más sencilla y en relación al otro término clave en el derecho de la crisis económica: ¿lo que es racional hoy puede ser irracional mañana? ¿O justamente lo contrario?

Es claro que esta serie de preguntas se formulan de una manera que alguien podrá juzgar como excesivamente retórica pero que, creo sinceramente, son imprescindibles porque hay una auténtica necesidad de que sean realizadas para poder poner en tela de juicio la afirmación que subyace a la utilización de estos conceptos por el derecho de la crisis económica: que nos encontramos ante la única respuesta normativa posible del derecho ante una determinada situación. Respuesta tan falta de sentido racional como sería la afirmación de que el tipo de regulación anterior a la aparición (estallido) de la crisis económica era también, por racional (¿es que el Legislador y la Administración del momento adoptaban decisiones irracionales?), la única regulación posible. Viene bien recordar aquí esa afirmación -casi un mantra- de la exposición de motivos de la Ley 5/1996: "La racionalización del sector público es, pues, un proceso continuo cuyo fin último no es otro que la obtención de mayor eficiencia..."

$\mathrm{Y}$ todo esto tiene un interés mucho mayor si se reflexiona, jurídicamente, en una de las consecuencias de todo lo que se está hablando: el control judicial. Porque, efectivamente, el control realizado por el TC (si se trata de constitucionalidad de normas de rango legal) o por la jurisdicción contencioso-administrativa (ante medidas reglamentarias o puramente administrativas $)^{51}$, cuando opere sobre decisiones económicas cuya impugnación se base en conceptos de racionalidad, racionalización y sostenibilidad, definidos y concretados hoy, se va a llevar

49 Nótese la palabra "conceptualmente" que se utiliza en el texto y también la referencia a la "adición" de condiciones específicas. No se está diciendo en el texto que si la deuda sube cuantitativamente lo que era sostenible ayer no lo sea hoy. Es perfectamente posible que la sostenibilidad ya no se consiga con una deuda creciente o con un déficit rampante. No. Lo que refiero en el texto es que sin cambiar los parámetros de deuda y déficit de una Administración Pública, la sostenibilidad desaparece porque se introducen nuevas condiciones conceptuales (ahora la morosidad de la deuda comercial) para la afirmación de la sostenibilidad. Y que ello tiene unas consecuencias tremendas, dado el régimen jurídico existente para "recuperar" la sostenibilidad.

50 Un ejemplo de tono menor puede ilustrar perfectamente el plural (digamos) sentido del concepto de racionalización: el Ministro de Hacienda acaba de hacer público (27 de marzo de 2014) que en el Proyecto de Ley de racionalización del sector público y otras medidas de reforma administrativa que ya he citado en este trabajo, se insertará una enmienda que devolverá a los funcionario un "moscoso" de los que fueron suprimidos hará un par de años. Al margen del significativo detalle de que sea un miembro del Gobierno quien anuncie, como si nada, lo que se insertará en el Proyecto de Ley por la comisión parlamentaria correspondiente (lo que dice mucho de la indiferencia, real, de gobernar la crisis económica por Decreto-ley, lo que ha sido lo habitual, o por Ley) la cuestión nos presenta la maleabilidad del concepto de "racionalización" y la dificultad de establecer premisas teóricas tanto sobre su definición como sobre su funcionalidad técnica.

51 Por no referirme a la misma posibilidad de intervención del Tribunal de Justicia de la Unión Europea que, por cierto, ya ha tenido lugar y en relación a cuestiones decisivas en el desarrollo de la crisis, como muestra la Sentencia del Pleno de 27 de noviembre de 2012 y en la que lo que está controvertido a través de una petición de decisión prejudicial, es la misma reforma del art. 136 del TFUE. 
a cabo mucho tiempo después de adoptarse tales decisiones, en momentos, quizá, muy distintos de cuando se aprobaron, cuando ha podido cambiar el concepto (normativo) de sostenibilidad o las premisas del proceso (deductivo) de la racionalidad.

Porque, y pensando solo en España, ¿quién no tuvo que cambiar o, al menos, matizar su convicción sobre lo que era racional o irracional (conveniente, adecuado, imprescindible, obligado... también sirven estos conceptos) en aquellos tremendos y vertiginosos primeros días de mayo de 2010?52

Dejemos de lado esa pequeña apelación la realidad y sigamos con el proceso deductivo.

\section{LAS LEYES Y SUS TÍTULOS: LO DESCRIPTIVO Y LO NEUTRO. LO VALORATIVO Y LO ORIENTADO.}

El examen de la actividad del legislador desde el mero punto de vista de los títulos que coloca a las Leyes es siempre ilustrativo. En el caso que nos ocupa, más todavía.

Existe, claro está, un legislador neutro y descriptivo, que se mueve en los rótulos por el único afán de señalar con seguridad un objeto normativo: Ley de Expropiación Forzosa, Ley General del Sector Eléctrico, Ley General de Telecomunicaciones, Ley de Costas, Ley de Carreteras, por utilizar ejemplos de distintas épocas (que no refiero expresamente con referencias temporales) y de distintos sectores del ordenamiento jurídico también. Podríamos decir, sin miedo a la equivocación, que esa es la tónica habitual del legislador. En cuanto se refiere a la titulación, es un legislador descriptivo y neutro.

Pero hay excepciones a esa tónica general y la crisis económica ha abundado en ejemplos de lo que digo. En este trabajo, precisamente, se han podido advertir variados ejemplos de esa actividad ${ }^{53}$ que ha alcanzado, posiblemente, un punto de difícil superación con la Ley 27/2013, de Racionalización y Sostenibilidad de la Administración Local, conceptos ambos que se mueven en el plano de lo valorativo y orientado y con los que se recubre lo que no es sino una Ley de modificación de la Ley Reguladora de las Bases del Régimen Local (de 1985, y también de algunas otras, pero de mucha menor importancia en el ámbito de lo modificativo), título que es el que debiera haber sido utilizado caso de decidir moverse el Legislador en ese plano descriptivo y neutro que refería ${ }^{54}$.

La enseñanza, por cierto, es un buen ejemplo -casi testigo- de esa ambivalencia en lo que persigue el Legislador. Antes refería la existencia de un Real Decreto-Ley, el 14/2012, de 20 de abril, de medidas urgentes de racionalización del gasto público en el ámbito educativo, pero los ejemplos no se acaban ahí. Hubo, sí, un legislador neutro y descriptivo en materia de enseñanza que aprobó la Ley General de Educación (1970), la Ley de Ordenación General del Sistema Educativo (1990) o la Ley Orgánica de Educación (2006), pero también, y en contraste con ellas, se insertaron en el largo iter legislativo español relativo a la enseñanza la Ley Orgánica de Calidad de la Educación (2002) o la más reciente Ley Orgánica para la Mejora de la Calidad Educativa (2013, ley perteneciente al período de la crisis económica pero no insertable en sus premisas generales sino con un propio desarrollo autónomo) títulos en los que la referencia a la "calidad" juega un papel semejante al que, en otros planos, se atribuye a la "racionalización".

Porque, efectivamente, ese es el papel que cumple el legislador valorativo y orientado en sus títulos. Racionalización, sostenibilidad, calidad, son conceptos con más o menos soporte normativo definitorio y limitador (bastante claro, pese a la mutabilidad, en la sostenibilidad, nulo en lo relativo a la racionalización o a la calidad que son conceptos puramente valorativos) y que exigen, inevitablemente, un trabajo de interpretación jurídica para dilucidar el contenido ínsito en esos conceptos. Y, obviamente, a ello podría seguir -debería seguir- otro trabajo también desarrollado en el plano de la interpretación jurídica para juzgar en la medida de lo posible de la real adecuación de esos conceptos -racionalización, sostenibilidad, calidad- al contenido de las decisiones normativas utilizadas.

Si siempre la Ley es (y debe ser) concreción en forma normativa de un programa político que ha gozado de la confianza del pueblo (en los sistemas democráticos), a veces el legislador valorativo y orientado incorpora el contenido del discurso político no solo al mandato normativo sino también a la rotulación que le precede. Es una característica que debe ser notada. Sin más.

52 Días en los que cambió a nivel europeo y, por supuesto, en el plano español también, la política que hasta entonces se había seguido para enfrentar la crisis económica. Con detalle vid. EMBID IRUJO (2011, pp. 42 y ss.).

53 Recuerdo ahora las Leyes o Decretos leyes estatales y autonómicos sobre la racionalización del sector público, o la racionalización del sector educativo.

54 Es curioso que la otra "gran" reforma de la LBRL también recurriera al amparo del título valorativo y orientado. Recordemos, así, a la Ley 57/2003, de 16 de diciembre, de Medidas de Modernización del Régimen Local. La funcionalidad ahora cumplida por la "racionalización” y la "sostenibilidad" es realizada en 2003 por otro concepto: la "modernización". Pero, igualmente, no estamos sino ante una modificación de la LBRL. 


\section{DIVAGACIONES SOBRE LA TEORÍA DE LOS CONCEPTOS JURÍDICOS INDETERMINADOS. ALGUNAS PREGUNTAS SOBRE LO QUE PUEDA SER RACIONAL Y SOSTENIBLE EN EL ÁMBITO DE LA ORGANIZACIÓN TERRITORIAL DEL ESTADO Y DEL SISTEMA FINANCIERO.}

La utilización de conceptos como los que se están tratando en este trabajo, al moverse siempre en el ámbito de lo valorativo y, normalmente, estar alejados de excesivas precisiones jurídicas, permite que se entable una discusión acerca de su contenido. Discusión que no es cosa inusual en derecho, sino que pertenece al trabajo habitual de los juristas y es desarrollado, normalmente, dentro de las técnicas jurídicas vinculadas a los controles judiciales que deban tener lugar sobre normas o hechos que se quieran vinculados, ejecutores, de tales conceptos. En el fondo eso es lo que sucede cuando el trabajo del jurista se desarrolla en torno a lo que se han venido en llamar "conceptos jurídicos indeterminados" y sobre los que, necesariamente, debe existir una determinación (porque son, precisamente, conceptos jurídicos indeterminados). Y determinación que -es ésta otra premisa del trabajo jurídico que estoy describiendo- es posible alcanzarla con seguridad, de tal forma que puede llegarse a una concreción del concepto una vez que se han desechado las interpretaciones que, claramente, son contrapuestas al último sentido incluible en los vocablos manejados.

La cuestión es si este trabajo jurídico que habitualmente se desarrolla en torno a los conceptos jurídicos indeterminados se puede aplicar de la misma forma y con las mismas pretensiones de alcanzar resultados seguros en el marco de una crisis económica tan singular como la actual y aplicada a las cuestiones clave, no a las accesorias, en temas tan fundamentales como la organización territorial del Estado o el sistema financiero, que la crisis económica ha tratado y puesto en el lugar preferente de atención.

Más en concreto: ¿son la racionalidad o la racionalización conceptos jurídicos indeterminados pero susceptibles de determinación? ¿Podemos utilizar esas palabras con naturalidad en el lenguaje jurídico y a través de ellas llegar a la postulación de la anulación de decisiones administrativas (por los Juzgados y Tribunales del orden jurisdiccional contencioso-administrativo) o incluso legislativas (por el Tribunal Constitucional) por falta de racionalidad, por estar ausentes en las mismas cualquier atisbo de racionalidad o de racionalización y, por tanto, ser arbitrarias y contrarios al principio de prohibición de la arbitrariedad presente en el art. 9.3 CE?

Imaginemos, para poder llegar a algún tipo de conclusión, algunas preguntas vinculadas a cuestiones clave en la organización territorial del Estado (a) y sobre problemas que han aparecido en torno al sistema financiero durante la crisis (b).

a) El primer tipo de preguntas va a estar vinculado, normalmente, a la LRSAL, dada la incorporación expresa al título de esta Ley de los conceptos de racionalización y sostenibilidad pero también escribo algunas no estrictamente ceñidas al objeto material de la Ley 27/2013:

-¿Es racional dividir el territorio catalán en cuatro circunscripciones provinciales? ¿Es racional hacerlo en siete veguerías? O: ¿pueden establecerse escalas de racionalidad? Entonces y presupuesta la escala, ¿cuál de las opciones es la más racional?55

-Si el sistema de la LRSAL es el racional en cuanto a la atribución y configuración de las competencias municipales y el papel de las Diputaciones Provinciales como coordinadoras o, incluso, sustitutivas de la prestación de servicios por los Municipios, ipor qué la misma Ley cede a las Diputaciones Forales vascas la determinación prácticamente total del régimen jurídico de los municipios vascos hasta el punto de que puede decirse que se ha interiorizado en grandísima medida el régimen local allí? Si la decisión de la LRSAL es la racional -recuérdese el título de la Ley- ¿por qué no se le aplica, sin más, también al País Vasco? ¿Puede variar la racionalidad de una decisión normativa en torno a cuestiones básicas de la organización territorial del Estado en función de la situación geográfica del espacio territorial al que se aplica?

-¿Es más racional que los municipios puedan tener competencias solamente en medio ambiente urbano que tenerlas, en general, en medio ambiente como sucedía hasta ahora, con obligación, incluso, para los municipios de más de 50.000 habitantes de prestar servicios en materia de protección del medio ambiente? ¿La anterior situación era irracional, para ser coherentes en el proceso de razonamiento con las premisas de la LRSAL?

-¿Es racional que las competencias en materia de asistencia social pasen a la titularidad de las Comunidades Autónomas aun cuando, inmediatamente, se deleguen o intenten delegar algunas de ellas en los Municipios?

¿¿Cómo puede hacerse más racional el sistema autonómico español? O, dicho más directamente: ¿es racional el sistema autonómico español?

55 Como se podrá observar evito hablar aquí y en cualquier otro momento de la constitucionalidad de las opciones que voy presentando, porque lo racional, en hipótesis, conllevaría la necesidad de modificar el marco constitucional si la respuesta de racionalidad llevara a circular por camino distinto a aquél que está escrito en la norma suprema. Esa es una condición de cualquier pregunta en torno a la racionalidad de las decisiones. 
-O acordémonos del otro concepto que sí tenía una mayor concreción jurídica: ¿es sostenible financieramente el sistema autonómico español? O maticemos más: ¿cómo hacerlo más sostenible? O ¿cómo evitar los rasgos de insostenibilidad? Y profundicemos todavía más en la concatenación posible de preguntas: ¿Es esta concreta Comunidad Autónoma -póngase el ejemplo que se desee- sostenible financieramente?

Creo que la simple enumeración de las preguntas planteadas lleva a una conclusión fácil de extraer: La dificultad de vincular lo racional a las decisiones claves de la organización territorial del Estado y las dificultades también -aunque menores, pues hay definición normativa- de la aplicación del concepto de sostenibilidad financiera. Con lo que ello aboca, por coherencia intelectual, a la necesidad de relativizar, de matizar conceptos como el de racionalidad (y de sostenibilidad, por su mutabilidad francamente desconcertante que antes he notado) que implican esa idea de única determinación posible de soluciones en ese plano de decisiones básicas -digamos incluso constitucionales- de la organización territorial del Estado y que va seguida, inmediatamente, de una Ley de racionalización (la racionalidad en marcha).

b) Pero también nos podemos imaginar la formulación de preguntas vinculadas al sistema financiero, por hablar de un ámbito en el que la atención del Legislador (y del Gobierno, y de la Administración, y del Banco de España, y del Banco Central Europeo... ) ha recaído desde 2009 continua y singularmente, con decisiones, además, de muy distinto contenido, desde los sistemas institucionales de protección -¿quién se acuerda ahora de ellos?-, al ejercicio de la actividad de las Cajas a través de una fundación bancaria:

-¿Es racional implantar sistemas de ayudas generalizadas a prácticamente cualquier Caja de Ahorros o Banco en dificultades?

- ¿Es racional, o más racional, actuar como se ha hecho en los Estados Unidos, mayoritariamente, dejando desaparecer, por ejemplo, los cinco bancos industriales que existían en 2007 y de los que no hay ya ni recuerdo?

- ¿Lo racional es ayudar solamente a todas las entidades financieras que presenten riesgo sistémico y dejar a su suerte al resto? Pero entonces: ¿quién determina lo que es riesgo sistémico? ¿A partir de qué nivel de endeudamiento, de falta de solvencia o de falta de liquidez (o de las tres cosas juntas) se puede decir que se da tal riesgo sistémico en una determinada entidad? ¿Deberían las normas explicitar claramente lo que es riesgo sistémico hasta el punto de que la labor del aplicador consistiera en una mera labor de concreción? ¿Quién debiera elaborar y aprobar dichas normas ${ }^{56}$ ?

Claro que estas últimas preguntas no serían puramente inocuas pues si la racionalidad es un concepto jurídico cuya falta de respeto conduce a afirmar la arbitrariedad (del legislador o de la administración) la consecuencia también podríamos formularla en forma de preguntas o, al menos, los juristas estaríamos obligados a pensar en ellas:

¡¿Esa determinación general de lo sistémico es susceptible de control judicial?

-¿Y la concretización de lo sistémico?

Y si respondemos de forma negativa a las anteriores preguntas o a alguna de ellas, ¿no nos encontraríamos ante un reverdecimiento de la teoría -que todos creíamos preterida- de los actos políticos?

Porque, entonces, deberíamos concluir, simplemente, en que racional y sostenible financieramente es lo que deciden los órganos competentes en cada caso para adoptar las decisiones correspondientes, siendo los elementos de competencia y procedimiento, así como la protección de los derechos fundamentales en el caso de que pudieran ser afectados, los únicos susceptibles de control jurisdiccional [cfr. art. 2 a) LJCA] pero ello, obviamente, no afecta para nada al fondo del asunto.

El pensar que cuestiones como éstas puedan escaparse a cualquier tipo de control (constitucional, judicial ordinario, del Tribunal de Justicia europeo, en su caso) no es plato de gusto de servir para ningún jurista imbuido plenamente -como es mi caso- de los principios del Estado de Derecho al que se vincula nuestra Constitución (art. 1) por lo que en modo alguno querría llegar a semejantes conclusiones. No obstante, el proceso discursivo realizado en este apartado del trabajo informa claramente de las dificultades de tal control cuando las premisas del mismo deberían estar vinculadas, de una forma u otra, a conceptos tan evanescentes -e instrumentalizados, a

56 Esta última pregunta nos sitúa directamente ante otra parte del problema que no quiero tratar aquí porque tiene una singularidad especial: la base democrática (y consiguiente responsabilidad) que deben tener quienes adoptan las decisiones claves en la vida económica y, obviamente, para superar la crisis económica en el marco de una política monetaria cedida por los países del euro al Banco Central Europeo y de importantes competencias políticas que ejercen determinadas instituciones europeas, de forma anecdótica el Parlamento Europeo. Este es un tema central en el debate jurídico-político y cada día lo será más y las respuestas a una cuestión capital para la vida de los ciudadanos europeos son, hasta el momento, completamente insatisfactorias. Y lo digo sin el más mínimo paliativo. 
veces- como los de sostenibilidad y racionalización tal y como se ha visto en las páginas anteriores. Continuemos para finalizar- el proceso de razonamiento con la exposición y pequeño comentario de una relativamente reciente Sentencia del Tribunal Constitucional en la que se va a poder observar claramente las dificultades que presenta el control -en este caso del Legislador- cuando tiene que operar sobre decisiones básicas en la crisis económica.

\section{Y FINAL: EL CONTROL DE LA ARBITRARIEDAD DEL LEGISLADOR EN LA CRISIS ECONÓMICA: EL EJEMPLO DE LA SENTENCIA DEL TRIBUNAL CONSTITUCIONAL 206/2013, DE 5 DE DICIEMBRE.}

Especificaba en el último párrafo las distintas posibilidades de control de que son susceptibles las medidas de los poderes públicos adoptadas en el marco de la crisis económica. Y de todas las manifestaciones mencionadas ha habido ejemplos en estos ya tan largos años de crisis. Decisión de tan gran calado como la aprobación del Tratado constitutivo del Mecanismo Europeo de Estabilidad (MEDE) fue objeto de una cuestión prejudicial y resuelto por la Sentencia del Tribunal de Justicia (en Pleno) de 27 de noviembre de 2012. El BVerfG ha emitido varias sentencias sobre cuestiones capitales en el ámbito de las decisiones europeas sobre la crisis económica ${ }^{57}$, la última es la de 18 de marzo de 2014 en la que también es objeto de tratamiento el Tratado de 2 de febrero de 2012 por el que se establece el Mecanismo Europeo de Estabilidad. Es evidente que el control en estas Sentencias (siempre afirmadoras en sus fallos de la adecuación a derecho -digámoslo genéricamente- de las decisiones europeas) ha sido una realidad y ha operado en torno a cuestiones difíciles y siempre complejas. No se han rechazado por inadmisibles las acciones sino que, al contrario, con argumentos que pueden o no compartirse, los órganos jurisdiccionales llamados a ello, han dado a los problemas planteados una respuesta basada en derecho.

Ahora, como decía, quiero tratar de una Sentencia del Tribunal Constitucional, la 206/2013, de 5 de diciembre (BOE núm. 7, de 8 de enero de 2014), resultado de la interposición de un recurso de inconstitucionalidad por medio del cual se somete a su juicio nada menos que una Ley de Presupuestos Generales del Estado (algunos de sus artículos), la Ley 2/2008, de 23 de diciembre, por la que se aprueban los Presupuestos Generales del Estado para 2009. Al margen de otras cuestiones, a mí me interesa en este lugar subrayar que la impugnación se basaba en la presunta comisión de una arbitrariedad por el Legislador. Y arbitrariedad que hacía referencia al fundamento mismo de tal Ley de Presupuestos Generales del Estado que se basaba en una estimación del crecimiento del PIB del $1 \%$ para 2009 y conforme a esa estimación se adoptaban las grandes decisiones económicas, contenido habitual de las Leyes de Presupuestos.

Los impugnantes (más de 50 diputados del Grupo Parlamentario Popular) consideran dicha decisión como arbitraria, en cuanto ausente de racionalidad, y como tal contraria al mandato del art. 9.3 CE ${ }^{58}$ de la "interdicción de la arbitrariedad de los poderes públicos" 59 . Y la arbitrariedad se basaba en que para los impugnantes el conjunto de los analistas (que singularizan en un informe de FUNCAS) preveía un crecimiento negativo del o'9\%, mientras que, como he dicho, los Presupuestos Generales del Estado se basaban en un crecimiento positivo del 1\%60.

Ello, como digo, sería para los impugnantes arbitrario por falta de racionalidad. Ese tipo de razonamiento ya había sido expresado anteriormente por el TC en su Sentencia 13/2007, de 18 de enero, f.j. 4, donde el TC expresaba que su misión consistía en examinar si la norma impugnada "carece de toda explicación racional, lo que también evidentemente supondría una arbitrariedad, sin que sea pertinente realizar un análisis a fondo de todas las motivaciones posibles de la norma y de todas sus eventuales consecuencias".

Esta frase será recordada, precisamente, por la STC 206/2013 que ahora comento que en su f.j. 8 también afirmará que la misión del TC es "controlar la adecuación a la Constitución de las leyes sin imponer restricciones indebidas al Poder Legislativo y respetando sus opciones políticas y, en concreto, extremando el cuidado cuando se trata de aplicar preceptos generales e indeterminados, como es el de interdicción de la arbitrariedad".

Estas últimas palabras son bien singulares en relación a lo que en este momento estoy tratando y, en general, he referido a lo largo del trabajo: la interdicción de la arbitrariedad de los poderes públicos contenida en el art. 9.3 CE constituye un precepto "general e indeterminado" y hay que extremar el cuidado cuando se trata de aplicarlo. Como veremos justo a continuación, el TC va a cumplir esa autodirectriz en gran medida y, en mi opinión, de forma enteramente "razonable". ahora.

57 Las he estudiado en EMBID IRUJO (2012, pp. 57 y ss.) A la bibliografía que allí se contiene sobre dichas Sentencias me remito aquí

58 También consideran violentados otros preceptos que cito luego, pero la mención del art. 9.3 CE es esencial en el recurso.

59 Es evidente que en este punto debe realizarse una mención general y elogiosa de la obra de FERNÁNDEZ RODRIGUEZ (1998 y 2013 , entre otras posibles referencias, pero éstas bien sintomáticas).

60 Eso llevaba consigo para los impugnantes que no pudieran considerarse razonables las cifras económicas previstas en la Ley de Presupuestos para el desempleo, porque ese aumentaría previsiblemente dado el crecimiento negativo del o'9\% y no el crecimiento positivo del $1 \%$ sobre el que se partía y se adoptaban decisiones etc... 
Pues bien, el razonamiento de los impugnantes basado en esa presunta falsa fundamentación de los Presupuestos Generales del Estado para 2009, conduce a que se consideren violentados los arts. 134 (el relativo a la configuración jurídica de los Presupuestos Generales del Estado), 9 (en sus tres apartados), 14, 40.1, 66.2 CE, el texto refundido de la ley general de estabilidad presupuestaria de 2007 entonces vigente, el Reglamento del Congreso de los Diputados y algunas otras normas.

La respuesta del TC va a ser rechazar el recurso con distintos argumentos. Por ejemplo negando al texto refundido de la ley general de estabilidad presupuestaria su carácter de norma del bloque de la constitucionalidad, acudiendo a la propia doctrina del TC sobre la arbitrariedad, investigando sobre los antecedentes de la Ley, lo sucedido en la tramitación parlamentaria etc...

Es decir, el TC no declara inadmisible el recurso o, sin más, lo rechaza sino que da una respuesta jurídica en torno a las alegaciones de los impugnantes concluyendo en que no habría arbitrariedad sino que, por el contrario y en función de todas las argumentaciones que utiliza y que ahora no reproduzco, se habría dado una "respuesta racional" a las previsiones macroeconómicas de que partía la Ley de Presupuestos Generales del Estado para 2009 (y previamente el Proyecto de Ley del Gobierno).

Todo ello es muy interesante jurídicamente, pero lo que me importa aquí sobremanera y a los efectos del discurso que estoy realizando, es el último párrafo de la intervención del TC en este f.j. $8^{\circ}$ y, sobre todo, sus últimas frases que reproduzco a continuación:

"En fin, las estimaciones de crecimiento que sustentan el presupuesto impugnado no eran, de acuerdo con el canon de enjuiciamiento que nos corresponde emplear, carentes "de toda explicación racional”, sino que venían avalados por el propio proceso de elaboración del presupuesto que en ningún caso puede garantizar que las previsiones de crecimiento económico que sirven como base para la elaboración de los presupuestos generales del Estado se vean cumplidas. Así resulta además evidente si se examina, obviamente en retrospectiva, el comportamiento real del PIB en el ejercicio de 2009. Según la demanda, la media de las previsiones de los analistas estimaba la caída del PIB en un o'9 por 100, por lo que reprocha a la Ley de presupuestos que asumiese como válido un incremento del 1 por 100 (esto es, 1'9 puntos por encima de la citada media). Pues bien, la caída real del PIB en ese ejercicio, de acuerdo con los datos oficiales publicados por la agencia europea Eurostat, resultó ser de 3'7 puntos. Todo lo anterior permite desestimar la tacha de arbitrariedad". (Es evidente que el resalte tipográfico es mío).

La cuestión planteada y la forma de resolución es interesantísima, como bien se habrá podido comprender, pues se centra en el instrumento primordial de conducción de la actividad económica tal y como siempre se ha pensado que eran los Presupuestos Generales del Estado61. Y es claro que este instrumento -y su control- es y seguirá siendo clave en situaciones jurídicas y normales que no planteen las características de excepcionalidad con las que actualmente vivimos.

De la misma forma el problema jurídico y su forma de resolución por parte del TC permite comprender bien a lo vivo los límites de determinados discursos jurídicos aparentemente claros y, consiguientemente, también las limitaciones del control jurisdiccional (el del TC) en una situación con las características de especialidad que tiene la actual crisis económica y sobre las que nunca se insistirá bastante. En concreto y en el marco de una crisis económica que, como dije en I), primero fue global y luego europea sustancialmente, y con instrumentos para luchar contra esa crisis que en buena medida y en los países del euro y también en el caso de los que solo son miembros de la UE se han trasladado fuera de las fronteras nacionales ${ }^{62}$, pretender plantear controles judiciales limitados al ámbito propio territorial y en relación a los instrumentos (escasos) con los que cuentan los Gobiernos y los Parlamentos, es posible hacerlo, sí, pero en la mayor parte de los casos ello desembocará en la frustración por la imposibilidad de desprender -en la mayor parte de las ocasiones también, insisto - las últimas consecuencias de determinado tipo de razonamiento jurídico a través de unos instrumentos jurídicos muy estrechos en relación al amplio número de variables (también jurídicas) que tienen que ser tenidas en cuenta ${ }^{63}$.

61 Claro que todo esto nos llevaría mucho más lejos: imaginemos un trabajo científico consistente en un examen conjunto de las leyes de presupuestos de todos estos años de crisis económica. Lo que se ha cumplido de ellas y lo que no. El resultado de ese trabajo ya lo podemos imaginar: la constatación de las múltiples, continuas, modificaciones de sus previsiones que han tenido lugar... en muchos casos a los pocos días de entrar en vigor, como ha sucedido en el caso de los Presupuestos para el año 2014 con el Real Decreto-Ley 1/2014, de 24 de enero, en materia de infraestructuras y transporte y otras medidas económicas que añade una nueva disposición adicional a la Ley de Presupuestos... del año 2014, o, incluso, antes de hacerlo, como ya sucedió hace algunos años. Modificaciones que en muchos supuestos operan contra los mismos supuestos fácticos que fundamentaron la aprobación de tales Leyes. Y en cualquier caso y sin hablar de las modificaciones, reiteración continua, inmisericorde, de los supuestos de que partía cada una de las Leyes de Presupuestos.

62 Viene bien aquí, otra vez, el recuerdo al trabajo de CARRERA (2013).

63 Volviendo a la situación de 2009, vendría bien recordar los trastornos generales de la economía europea que comenzaban a manifestarse con los problemas de la deuda griega y luego portuguesa e irlandesa (los países que fueron luego rescatados, pero también comenzaban a dar signos preocupantes las economías italiana y española). Y los consiguientes "rescates" que ya operarían con posterioridad. Todo eso 
No queda otro remedio desde los parámetros y principios del Estado de Derecho que continuar utilizando -y fomentando- el principio de control absoluto de la actividad de los poderes públicos a través de los múltiples y variados instrumentos con que se cuentan, pues solo de esa forma la libertad y dignidad de los ciudadanos tendrá ocasión de manifestarse continua y plenamente. Pero lo que también y al mismo tiempo hay que postular es una prudencia en la utilización de dichos instrumentos de control para no llegar a situaciones de tanta contradicción e incongruencia como la que nos muestra esta STC: ¿qué más da, podríamos decir, que se partiera de un supuesto de crecimiento o de decrecimiento si la consecución de esas cifras, en la realidad, no depende en gran medida de la actuación del Legislador o Gobierno nacional sino de imponderables que juegan de una forma incontrolable por aquél a quien los respectivos sistemas constitucionales le dan la máxima responsabilidad y competencia para ello? Frente a previsiones de analistas (economistas, y remito a lo antes dicho sobre su papel en la crisis económica) de decrecimiento del o'9\% y de otros (economistas) de crecimiento del 1\%, la realidad nos presentó un decrecimiento del 3'7\%.

Prudencia que debe ser pedida en la utilización de los mecanismos del control constitucional y judicial de la actividad del Legislador y del Gobierno ${ }^{64}$ y prudencia que igualmente hay que exigir también al Legislador y al Gobierno en la utilización de conceptos tales como los de racionalización, sostenibilidad y otros, que han formado, como se ha advertido en el trabajo, el entramado intelectual del derecho de la crisis económica en la mayor parte de sus manifestaciones. La apelación continua a razonabilidad y sostenibilidad ha tenido el efecto de presentar como inevitables las decisiones -normativas y administrativas- adoptadas en cada momento $0^{65}$, pero tal modo de proceder es más propio del derecho natural (entendido al modo clásico) que del derecho positivo.

\section{BIBLIOGRAFÍA.}

ALVAREZ CONDE E. y SOUTO GALVÁN C. (dirs.) (2012): La constitucionalización de la estabilidad presupuestaria, Universidad Rey Juan Carlos, Madrid, 457 pp.

ASOCIACIÓN DE LETRADOS DEL TRIBUNAL CONSTITUCIONAL (edit.) (2012): La Constitución Económica, Centro de Estudios Políticos y Constitucionales, Madrid, 2012.

BALAGUER CALLEJÓN F. (2013): "Crisis económica y crisis constitucional en Europa", en REDC 98, pp.91-107.

BASSOLS COMA M. (1985): Constitución y sistema económico, Tecnos, Madrid.

BASSOLS COMA M. (2012): “La crisis económica y sus repercusiones en el Derecho Público económico; el principio de buena regulación económica, supresión de cargas administrativas y constitucionalización de la estabilidad presupuestaria", NUE, 325, pp. 3-15.

BASSOLS COMA M. (2012): "La reforma del Artículo 135 CE y la constitucionalización de la estabilidad presupuestaria: el proceso parlamentario de elaboración de la reforma”, REDA 155, pp. 21-42 y en las pp. 275-284 de J.R. FUENTES I GASÓ y otros, op. cit.

CALLIESS C. (2012): "Finanzkrisen als Herausforderung der internationales, europäischen und nationales Rechtsetzung”, en las pp. 115 y ss. de VVDStRL 71, De Gruyter, Berlin.

CARRERA HERNÁNDEZ F.J. (2013): “Nuevos instrumentos para la gobernanza económica en la Unión Europea: el procedimiento de prevención y corrección de los desequilibrios macroeconónicos-PDM", Revista de Derecho Comunitario Europeo, 44, pp. 63-100.

CASSESE S. (2009): Il diritto globale. Giustizia e democrazia oltre lo Stato, Einaudi, Torino, 244 pp.

CASSESE S. (2012): La nuova costituzione económica, Laterza, $5^{\text {a }}$ ed., Bari, 371 pp.

CAZORLA PRIETO L.M. (2009): Crisis económica y transformación del Estado, Aranzadi y Thomson-Reuters, Cizur Menor, 180 pp.

CAZORLA PRIETO L.M. (2010): El Gobierno de la globalización financiera: una aproximación jurídica, Real Aca-

tenía y tiene repercusiones internas en el desarrollo de las vidas económicas de otros Estados, Estados que, presuntamente, pretendían dirigir esa vida económica contando con el instrumento primordial de sus Presupuestos. Vana ilusión.

64 Nada que decir sobre la interposición del recurso de inconstitucionalidad en un momento determinado y en relación a las cifras que en ese momento manejaban los impugnantes; todo ello es perfectamente legítimo y, además, una forma de poner en marcha mecanismos constitucionales de control de la actividad de los poderes públicos. Pero ¿no pudo retirarse tal recurso de inconstitucionalidad una vez hechas públicas por Eurostat las cifras reales de déficit del 2009, muy alejadas, es claro, de las previsiones del Gobierno pero también, es obvio, de las que manejaban los impugnantes?

65 Decisiones que -es obvio decirlo pero creo conveniente volver a insistir en ello- tienen un fundamento legítimo en cuanto al fondo de las mismas en las mayorías políticas decididas por la ciudadanía en cada momento. 
demia de Jurisprudencia y Legislación, Madrid, 193 pp.

D’ALBERTI M. (2008): Poteri pubblici, mercati e globalizzazione, Il Mulino, Bologna, 154 pp.

DE LA DEHESA G. (2009): La primera gran crisis financiera del siglo XXI. Orígenes, detonantes, efectos, respuestas y remedios, Alianza Editorial, Madrid, $583 \mathrm{pp}$.

DíEZ SÁNCHEZ J.J. (coord.) (2013): La planta del gobierno local, Asociación Española de Profesores de Derecho Administrativo-Fundación Democracia y Gobierno Local, Madrid.

EMBID IRUJO A. (1997): “La utilización racional de las aguas y los abastecimientos urbanos. Algunas reflexiones”, Revista Aragonesa de Administración Pública, pp. 209-219.

EMBID IRUJO A. (2009): El derecho de la crisis económica, Universidad de Zaragoza, Zaragoza, 125 pp.

EMBID IRUJO A. (2001): “El derecho público de la crisis económica”, en A. BLASCO ESTEVE (coordinador), EI Derecho Público de la crisis económica. Transparencia y sector público. Hacia un nuevo Derecho Administrativo, INAP, Madrid, pp. 21-120.

EMBID IRUJO A. (2012): La constitucionalización de la crisis económica, lustel, Madrid, 2012, 151 pp. Otro trabajo propio con el mismo nombre, pero concluido antes y con algo menos de información y perspectiva, por tanto, en el volumen de la Asociación de Letrados del Tribunal Constitucional La Constitución económica, pp. 127-226, y citado anteriormente que recoge las ponencias presentadas a las XVII Jornadas organizadas por dicha Asociación y que se celebraron en Cádiz a comienzos de noviembre de 2011. En el volumen se recogen también los debates a que dieron lugar la presentación de las aportaciones de J. BARNES, E. ALBERTI ROVIRA y J.Ma BAÑO LEÓN así como de la mía propia.

EMBID IRUJO A. (2014): “Informe general”, en el Anuario Aragonés del Gobierno Local 2013, Institución Fernando el Católico, Zaragoza.

EMBID IRUJO J.M. (2013): Sobre el derecho de sociedades de nuestro tiempo. Crisis económica y ordenamiento societario, Comares, Granada, 158. pp.

FERNÁNDEZ-RODRIGUEZ T.R.: (1998): De la arbitrariedad del legislador. Una crítica de la jurisprudencia constitucional, Civitas, Madrid, $172 \mathrm{pp}$.

FERNÁNDEZ RODRIGUEZ T.R. (2013): Sobre los límites constitucionales del poder discrecional. Lección jubilar del profesor Tomás-Ramón Fernández, pronunciada en Donostia-San Sebastián, el 12 de mayo de 2011 pero editada en la fecha que señalo.

FONT I LLOVET T. y GALAN GALAN A: (2013): “Racionalización y sostenibilidad de la Administración local: ¿es ésta la reforma?", en las pp. 11-43 de Anuario del Gobierno Local 2012, Institut de Dret Public, Barcelona.

FUENTES I GASÓ J.R., GIFREU I FONT J. y CASADO CASADO L. (coordinadores) (2012): Estructuras administrativas y racionalización del gasto público. Problemas actuales de la expropiación forzosa. La reforma de los entes locales en Italia en el contexto de la crisis económica, INAP, Madrid, 433 pp.

GARCÍA ROCA J. y MARTÍNEZ LAGO M.A. (2013): Estabilidad presupuestaria y consagración del freno constitucional al endeudamiento, Civitas y Thomson Reuters, Cizur Menor, 202 pp.

GIANNINI M.S. (1977, cit. por la edición de 1993) Diritto pubblico dell'economia, Il Mulino, 345 pp.

JIMÉNEZ ASENSIO R. (2014): “La reforma local: primer análisis de la Ley de racionalización y sostenibilidad de la Administración local. Contexto, elementos estructurales y algunas pautas interpretativas para la aplicación de un marco normativo complejo", en el Anuario Aragonés del Gobierno Local 2013, Institución Fernando el Católico, Zaragoza.

MALARET E. (2013): “Le malaise de la globalisation. La crisis économique et les déséquilibres dans la structure des pouvoirs de decisión. Pour un constitutionnalisme économique européen ouvert”, en European Publica Law Series/Bibliothéque de Droit Public Européen, vol. CVII, pp. 183 y ss.

MARICHAL C. (2012): Nueva historia de las crisis financieras. Una perspectiva global, 1873-2008, Ramdom House Mondadori, Barcelona, $420 \mathrm{pp}$.

MARTIN-RETORTILLO S. (1991): Derecho Administrativo Económico I, La Ley, Madrid, 504 pp.

MENÉNDEZ A.J. (2012): De la crisis económica a la crisis constitucional de la Unión Europea, Eolas ediciones, León, $116 \mathrm{pp}$. 
MIGUEL BÁRCENA J. de (2011): El Gobierno de la economía en la Constitución europea. Crisis e indeterminación institucional, Bosch editor, Barcelona, $171 \mathrm{pp}$.

MONGOUACHON C. (2012): "Les débats sur la Constitution économique en Allemagne”, en Revue française de Droit constitutionnel, 90, pp. 303-337.

MONTOYA MARTIN E. (2012): "Reflexiones sobre el sector público instrumental en un contexto de crisis económica: la inaplazable hora de la racionalización”, en las pp. 15 y ss. de FUENTES I GASÓ y otros (op. cit.).

MUÑOZ MACHADO S. (dir) (2009-2013): Derecho de la regulación económica, lustel, Madrid, diez tomos algunos divididos en dos volúmenes.

MUÑOZ MACHADO S. (2011): Tratado de Derecho Administrativo y Derecho Público General, I, $3^{\mathrm{a}}$ ed., lustel, Madrid, 1063 pp.

NIPPERDEY H.C (1950): “Die Grundprinzipien des Wirtschaftsverfassungsrechts”, DRZ 5.

NOGUEIRA LÓPEZ A. (2011): “Crisis económica y cambios estructurales en el régimen de ejercicio de actividades ¿reactivación económica o pretexto desregulador, en A. BLASCO ESTEVE (coordinador), El Derecho Público de la crisis económica. Transparencia y sector público. Hacia un nuevo Derecho Administrativo, INAP, Madrid, pp. 121-190.

OFFE C. (2013): “Europa acorralada”, REDC 98, pp. 13-37.

PETRINI R. (2010): Proceso a los economistas, Alianza editorial, Madrid, 208 pp.

RODRIGUEZ DE SANTIAGO J. M M $^{\mathrm{a}}$ y VELASCO CABALLERO F. (2010): Estado y Mercado en situación de crisis, Anuario de la Facultad de Derecho de la Universidad Autónoma de Madrid, 14, 2010, 167 pp.

RODRÍGUEZ ZAPATERO J.L. (2013): El dilema. 600 días de vértigo, Planeta, Barcelona.

ROUBINI N. y MIHM S. (2010): Cómo salimos de ésta, (en el inglés original un título menos “comercial” Crisis económics), Destino, Barcelona, $567 \mathrm{pp}$.

SCHORKOPF F. (2012): "Finanzkrisen als Herausforderung der internationales, europäischen und nationales Rechtsetzung”, en las pp. 184 y ss. de VVDStRL 71, De Gruyter, Berlin.

SOSA WAGNER F. y FUERTES M. (2011): Bancarrota del Estado y Europa como contexto, Marcial Pons, Madrid, $174 \mathrm{pp}$.

STOBER R. (1992): Derecho Administrativo económico, Ministerio para las Administraciones Públicas, Madrid, $398 \mathrm{pp}$.

VILLAR ROJAS F.J. (2012): “Crisis económico-financiera; Crisis de la Administración Pública”, en las pp. 43 y ss. de GONZÁLEZ SANFIEL A.M. (dir.), El derecho ante la crisis: nuevas reglas de juego, Atelier, Barcelona, 222 pp. 
NORMA, ECONOMÍA Y LENGUAJE EN EL DERECHO DE LA CRISIS ECONÓMICA. EL CONTROL JUDICIAL DE LA ACTIVIDAD ADMINISTRATIVA EN LA ECONOMÍA. ALGUNAS REFLEXIONES

Antonio Embid Irujo 